\title{
Neurotrophin gene augmentation by electrotransfer to improve cochlear implant hearing outcomes
}

Jeremy L. Pinyon ${ }^{1}$, Georg von Jonquieres ${ }^{1}$, Edward N. Crawford ${ }^{1}$, Mayryl Duxbury ${ }^{1}$, Amr Al Abed $^{2}$, Nigel H. Lovell ${ }^{2}$, Matthias Klugmann ${ }^{1}$, Andrew K. Wise ${ }^{3}$, James B. Fallon ${ }^{3}$, Robert K. Shepherd ${ }^{3}$, Catherine S. Birman ${ }^{4,5}$, Waikong Lai ${ }^{4}$, David McAlpine ${ }^{6}$, Catherine McMahon 6 , Paul M. Carter ${ }^{7}$, Ya Lang Enke, James F. Patrick ${ }^{7}$, Anne G.M. Schilder ${ }^{8}$, Corinne Marie ${ }^{9}$, Daniel Scherman ${ }^{9}$, Gary D. Housley ${ }^{1}$

${ }^{1}$ Translational Neuroscience Facility \& Department of Physiology, School of Medical Sciences, UNSW Sydney, New South Wales, Australia; ${ }^{2}$ The Graduate School of Biomedical Engineering, UNSW, Sydney, New South Wales, Australia; ${ }^{3}$ Bionics Institute, St Vincent's Hospital, Melbourne, Australia, the Department of Medical Bionics, University of Melbourne, Melbourne, Australia, Department of Otolaryngology, University of Melbourne, Melbourne, Australia; ${ }^{4}$ Department of Otolaryngology, Royal Prince Alfred Hospital, Camperdown, NSW, Australia, ${ }^{5}$ The Sydney Cochlear Implant Centre, Royal Institute of Deaf and Blind Children, Gladesville, NSW, Australia Department of Linguistics, Facility of Human Sciences, Macquarie University, North Ryde, Australia; ${ }^{6}$ The Hearing Hub, Macquarie University, Sydney, Australia, The HEARing Cooperative Research Centre, Melbourne, Australia; Cochlear Ltd, Sydney, Australia; ${ }^{8}$ Ear Institute, University College London, London, United Kingdom; ${ }^{9}$ Laboratory of Chemical and Biological Technologies for Health, Université Paris Descartes, Sorbonne-Paris-Cité, F-75006 Paris, France, CNRS, UTCBS UMR 8258, F-75006 Paris, France, Chimie ParisTech, PSL Research University, UTCBS, F-75005 Paris, France, INSERM, UTCBS U 1267, F-75006 Paris, France.

Keywords: Brain derived neurotrophic factor; neurotrophin-3; bionic array directed gene electrotransfer; auditory nerve fibre regeneration; gene therapy; sensorineural hearing loss.

Address for correspondence:

Gary Housley

Department of Physiology

School of Medical Sciences

UNSW Sydney

NSW 2052

Australia

Email: g.housley@unsw.edu.au

Tel: +61 293851057 


\section{Abstract}

This Review outlines the development of DNA-based therapeutics for treatment of hearing loss, and in particular, considers the potential to utilize the properties of recombinant neurotrophins to improve cochlear auditory (spiral ganglion) neuron survival and repair. This potential to reduce spiral ganglion neuron death and indeed re-grow the auditory nerve fibres has been the subject of considerable pre-clinical evaluation over decades with the view of improving the neural interface with cochlear implants. This provides the context for discussion about the development of a novel means of using cochlear implant electrode arrays for gene electrotransfer. Mesenchymal cells which line the cochlear perilymphatic compartment can be selectively transfected with (naked) plasmid DNA using array - based gene electrotransfer, termed 'close-field electroporation'. This technology is able to drive expression of brain derived neurotrophic factor (BDNF) in the deafened guinea pig model, causing re-growth of the spiral ganglion peripheral neurites towards the mesenchymla cells, and hence into close proximity with cochlear implant electrodes within scala tympani. This was associated with functional enhancement of the cochlear implant neural interface (lower neural recruitment thresholds and expanded dynamic range, measured using electrically - evoked auditory brainstem responses). The basis for the efficiency of close-field electroporation arises from the compression of the electric field in proximity to the ganged cochlear implant electrodes. The regions close to the array with highest field strength corresponded closely to the distribution of bioreporter cells (adherent human embryonic kidney (HEK293)) expressing green fluorescent reporter protein (GFP) following gene electrotransfer. The optimization of the gene electrotransfer parameters using this cell-based model correlated closely with in vitro and in vivo cochlear gene delivery outcomes. The migration of the cochlear implant electrode arraybased gene electrotransfer platform towards a clinical trial for neurotrophin-based enhancement of cochlear implants is supported by availability of a novel regulatory compliant mini-plasmid DNA backbone (pFAR4; plasmid Free of Antibiotic Resistance v.4) which could be used to package a 'humanized' neurotrophin expression cassette. A reporter cassette packaged into pFAR4 produced prominent GFP expression in the cat basal turn perilymphatic scalae, which closely models the human cochlea. More broadly, close-field gene electrotransfer may lend itself to a spectrum of potential DNA therapeutics applications benefitting from titratable, localized, delivery of naked DNA, for gene augmentation, targeted gene regulation, or gene substitution strategies. 


\section{Overview}

\subsection{Inner ear gene delivery}

The translational potential of gene therapy in the inner ear is developing considerable prominence within the burgeoning domain of hearing therapeutics. This is founded upon successes in pre-clinical models that have utilized directed manipulation of gene expression to investigate developmental and physiological processes of hearing and balance at the molecular level. Modalities used for expression of recombinant proteins include ballistics ('gene gun'based delivery of gold particles coated with DNA) (Belyantseva, 2009; Zhao et al., 2012), lipofectamine-based transduction, and replication-deficient viral-vector-based approaches (typically adenovirus, or adeno-associated virus (AAV)) (Akil et al., 2012; Kelley, 1997; Pan et al., 2013; Wise et al., 2010). Targeting of gene expression is highly variable, being regulated to some extent by use of promoters biasing translation of recombinant proteins to subsets of the highly differentiated cell types in the inner ear (Praetorius et al., 2010). In the case of viral vectors, selection between different viral capsid serotypes has a major effect on cell tropism, for example use of AAV1 enabled inner hair cell-specific expression of vesicular glutamate transporter-3 (VGLUT3) to restore hearing in VGLUT3 null mice (Akil et al., 2012), while use of the Anc80L65 serotype enables transfection of outer hair cells alongside inner hair cells (Landegger et al., 2017). In the vestibular system, the Ad28 serotype of adenovirus has been shown to selectively enable expression in supporting cells (Schlecker et al., 2011). Electroporation offers an alternative approach for inner ear gene delivery that has largely been constrained to in vitro tissue culture studies and in utero gene transfer (Driver et al., 2010; Wang et al., 2012). Typically plate electrodes are placed across the target tissue and a brief train of voltage pulses is used to drive plasmid DNA incorporating various expression cassettes into inner ear cells via conventional 'open-field' electroporation (Xiong et al., 2014), for example transfecting organ of Corti hair cells and supporting cells. Directed electrotransfer of naked DNA to targets within the cochlea via 'close-field' electroporation, where the electrodes are in a contiguous array, is proving highly effective both in situ and in vivo (Pinyon et al., 2018; Pinyon et al., 2014; Shepherd et al., 2014).

Investment in hearing gene therapy by industry will focus on rectification of monogenic disorders underlying profound loss of hearing (and / or balance), as well as rescue of acquired sensori-neural hearing loss (Lustig et al., 2012). A case in point is the first hearing gene therapy clinical trial supported by a consortium sponsored by Novartis Pharmaceuticals (Pharmaceuticals, 2019), which is directed to restore moderate to severe acquired hearing loss. This program utilizes an adenoviral vector (Ad(5)GFAP.HATH 1.11D; CGF166) encoding the 
human atonal homolog-1 transcription factor (referred to as Hath1, and in animals studies as Atoh1, also known as Math1), delivered into the scala vestibuli cochlear perilymph via injection through the stapedius bone and oval window membrane (Brough et al., 2016). This was founded upon pre-clinical studies of models of hair cell loss where Atohl expression successfully drove trans-differentiation of supporting cells into new sensory hair cells, with improvement in hearing and balance function (Baker et al., 2009; Husseman et al., 2009; Izumikawa et al., 2005; Kawamoto et al., 2003; Schlecker et al., 2011). This next generation hearing therapeutics, which seeks to restore sound transduction by creating new cochlear hair cells and establishing new auditory synapses with spiral ganglion neurons, is at the threshold of a quantum leap from current clinical management of inner ear disorders. However, such powerfully interventional molecular therapies require vigilance with regard to impacts on the complex signal transduction pathways both within and beyond the inner ear.

\subsection{A rationale for neurotrophic factor gene therapy to enhance the cochlear implant}

While moderate - to - severe levels of hearing loss can be treated by hearing aids, those with profound hearing disability are increasingly benefitting from cochlear implants, with well in excess of half a million people accessing this advanced medical bionics technology. In this domain, neurotrophin delivery integrated into the cochlear implantation procedure has been explored as a means of enhancing hearing performance with the 'Bionic Ear' (Budenz et al., 2012; Hendricks et al., 2008; Wise et al., 2016). This concept has largely been pursued in preclinical animal models using direct delivery of the neurotrophins to the cochlea (Landry et al., 2013; Leake et al., 2013; Miller et al., 2007; Ramekers et al., 2012; Wise et al., 2005), or by use of locally delivered viral vectors encoding these neurotrophins (Ramekers et al., 2012; Shibata et al., 2010; Wise et al., 2010). The pre-clinical studies utilising gene delivery approaches are complemented by a relatively smaller group of studies evaluating cell-based therapies, utilising encapsulated cells, such as choroid plexus-derived cells, which are known to produce a range of neurotrophic factors (Fransson et al., 2018; Pettingill et al., 2011; Wise et al., 2011). Studies in deafened cats with long-term osmotic minipump delivery, and in guinea pigs with adenovirus-based brain derived neurotrophic factor (BDNF) and neurotrophin-3 (NT3) delivery to scala media respectively, showed improved spiral ganglion neuron survival and significant re-generation of the spiral ganglion neurites, albeit with some over-extension of the fibres. While improved proximity between the cochlear implant electrodes and the peripheral auditory nerve fibres 'closes the neural gap' and improves the neural interface, excessive extension of the fibres has the potential to degrade the tonotopically-related neural recruitment 
(Leake et al., 2013). However, there is some evidence from the viral vector delivery studies that the extension of the spiral ganglion neurites may be directed outwards through the osseous spiral lamina and along the basilar membrane towards the cells producing the recombinant BDNF (Shibata et al., 2010). This tropism can be exploited with targeted gene delivery, to draw the auditory fibres to the cochlear implant array. While high efficiency and long-duration of expression of viral vector-based gene therapy is attractive in many applications, it may be problematic from a safety view-point with respect to recombinant neurotrophin expression cassette delivery to the cochlea. Several studies have shown that delivery of microlitre quantities of AAV vector to the perilymphatic compartment of the cochlea can result in significant off-target "leakage" of expression. For example, in the case of a translational model to restore hearing and balance in an Usher syndrome 1c mouse model, delivery of an Anc80L65 AAV-harmonin-b1 vector unilaterally via the cochlear round window membrane resulted in rescue of sound transduction in the untreated cochlea (Pan et al., 2017); evidently the virus reached there via the cochlear fluid, including perilymph within the cochlear aqueduct that connects to the subarachnoid space cerebral spinal fluid compartment, and beyond. Vestibular dysfunction was also rescued in these studies, highlighting the contiguous nature of the perilymphatic compartments in the inner ear. The potential detrimental impact of off-target AAV transfer to the CNS from the cochlea has been confirmed in another neonatal mouse study using a glial-derived neurotrophic factor (GDNF) - expressing AAV-5 vector (Akil et al., 2018). This study demonstrated spread of the AAV5-hGDNF vector from the cochlea to the CNS and spiral cord, presumably via the cochlea aqueduct, and this was associated with significant neurological dysfunction linked to broad loss of cerebellar Purkinje neurons, centrally-mediated hearing loss and retarded growth correlated with the AAV5-hGDNF vector titre (Akil et al., 2018). While it might be argued that patency of the cochlear aqueduct is not comparable in human cochlear implant candidates, spread of active viral particles is nevertheless a significant risk. Directed delivery of gene cassettes encoded by naked DNA to the cochlea, which is achievable using cochlear implant array - based electrotransfer, mitigates concerns linked to such viral vector off-target actions and may enable latent gene therapy applications.

The context of establishing a neurotrophin gene therapy strategy for engaging with sensorineural hearing loss also warrants reflection on species-specific, developmental, and injury status with respect to expression of neurotrophins and their receptors in the cochlea. For example, it is known that in the rodent, the weighting of expression of BDNF and NT-3 changes with cochlear maturation, where BDNF declines but NT-3 levels are sustained, while all 
cognate receptors (TrkB for BDNF, TrkC for NT-3 and $\mathrm{p} 75^{\text {ntr }}$, which transduces both BDNF and NT-3 at low affinity) are maintained by the spiral ganglion neurons (review by (Ramekers et al., 2012)). In the mouse cochlea, NT-3/TrkC signalling supports development of the basalmid cochlear innervation of hair cell innervation, while BDNF/TrkB signalling supports apical hair cell innervation. This base - apex gradient of NT-3 expression (by inner hair cells) reverses in the adult, while the TrkB/TrkC spiral ganglion expression, remains homogenous (Ramekers et al., 2012). Signalling via TrkB/ TrkC invokes tyrosine kinase activation and complex phosphorylation-dependent processes which include phospholipase $\mathrm{C}$ activation driving $\mathrm{Ca}^{2+}$ store release and $\mathrm{Ca}^{2+}$ entry. The latter contributes to axon guidance, established for BDNF in the brain and cochlea, which is likely mediated by PLC-DAG dependent activation of canonical transient receptor potential (TRPC) channels ( $\mathrm{Li}$ et al., 2005). Consistent with this, TRPC3 immunolabelling is pronounced in mouse and guinea pig spiral ganglion neurons, particularly in the peripheral neurites during the crucial neonatal window for innervation of the hair cells (Phan et al., 2010; Tadros et al., 2010), and is then elevated in the soma in adults.

In animal models, loss of cochlear hair cells associated reduction in neurotrophin production, causes atrophy of the peripheral spiral ganglion neurites in the osseous spiral lamina and subsequent progressive death of the neurons over periods of weeks to months (Fransson et al., 2017). Fortunately the human cochlea exhibits considerable resilience, with retention of much of the spiral ganglion neuron population for decades following loss of the hair cells (Leake et al., 1991; Nadol, 1997). This makes cochlear implants tenable as the primary treatment for profound hearing loss, and with regard to hearing therapeutics, makes treatment with neurotrophins attractive with regard to the bionic ear interface, both by mitigating progressive loss of spiral ganglion neurons, and if directed regulated re-growth towards the cochlear implant electrode array can be achieved, then finer control of neural recruitment may be possible, improving hearing performance.

Cochlear neurotrophin treatment has been broadly tested in deafened animal models with regard to cochlear implant performance. While characterisation of the extent of peripheral neurite regrowth is problematic, spiral ganglion neuron rescue by neurotrophin delivery has been examined with regard to measures such as electrically-evoked auditory brainstem response (eABR) thresholds and input/output functions. Findings from the acutely deafened guinea pig model with close-field BDNF gene electrotransfer outlined below (Pinyon et al., 2014), suggest that BDNF-induced improvement in spiral ganglion neuron health, measured by greater survival, increased soma cross-sectional area, and constrained peripheral neurite extension, do indeed confer improvements in control of cochlear implant- driven neural 
recruitment. However, clinical evidence that spiral ganglion survival and retention of auditory nerve fibres within the osseous spiral lamina correlates with hearing outcomes of cochlear implant subjects is equivocal. For example, an early study (Nadol et al., 2001) reported that spiral ganglion neuron counts were negatively correlated with single-syllable word recognition in eight cases with electrode array-type implants, and there was no difference in neuron survival relative to the opposite (non-implanted) cochleae. The latter in particular contrasts with the reported improved survival of spiral ganglion neurons with electrical stimulation alone in a deafened cat study (Leake et al., 1991), cautioning translational inferences from animal models. Data comparing word recognition scores via left and right ears for bilaterally implanted subjects, against post-mortem spiral ganglion neuron counts for six individuals clearly demonstrated a positive correlation (Seyyedi et al., 2014). This has been supported by a study across seventeen subjects which considered CNC word scores and spiral ganglion neuron counts in conjunction with confounders such as cochlear implantation - induced neoosteogenesis (negative) and fibrosis (no effect) (Kamakura et al., 2016).

With regard to clinical application of neurotrophins with the aspiration of enhancing cochlear implant performance, translational questions with finer granularity abound. For example, neurotrophin treatment alongside cochlear implants may alter the expression and properties of ion channels key to action potential initiation and propagation, which would therefore impact on the auditory coding and hence central auditory processing. In many cases the knowledge gained by undertaking a first-in-human trial is needed to provide the definitive insights which currently remain unanswered, or unanswerable in pre-clinical models.

\section{Cochlear implant electrode array - based gene electrotransfer' for localized gene delivery}

\subsection{Background to gene electrotransfer}

There has been a frameshift in understanding of pulsed electric field-based DNA transfer in recent years, with studies showing that electroporation is a misnomer in that plasmid DNA is too large to cross into cells through transiently generated pores in the plasma membrane, with associated electrophoretic translocation of the negatively charged DNA. Rather, it is now recognised that unlike small RNA and DNA oligonucleotide molecules, and fluorescent molecules such as propidium iodide, that migrate through these temporary membrane pores, plasmid DNA, which is MDa in size and approaches a hundred $\mathrm{nm}$ in diameter, is largely taken up by cells by active processes. Thus, the effect of the train of electric 
pulses that achieves such electroporation is of sufficient electric field strength that it drives the physical adherence of (plasmid) DNA to the cathode-facing surface of cells. This achieves inclusion of many thousands of these DNA molecules onto the plasma membrane, with internalization through endocytosis and pinocytotic mechanisms (Escoffre et al., 2011; Rosazza et al., 2016a; Rosazza et al., 2016b). The majority of these exogenous DNA molecules are then eliminated within lysosomes and by endonuclease activity, but a small fraction of the plasmid DNA (probably hundreds of copies) are transported to the nuclear pores, exiting from the transport vesicles and becoming established as extra-chromosomal (episomal) DNA. The episomal DNA is then transcribed to produce mRNA encoding the recombinant protein(s) (Pinyon et al., 2018). This plasmid DNA is characteristically resistant to degradation and after achieving detectable translation within a few hours, may support expression for many months (Wong et al., 2015). This process is therefore now more frequently referred to as DNA electrotransfer rather than electroporation. Key parameters for efficient expression of recombinant proteins using DNA electrotransfer tend to be related to the intrinsic biophysics of the gene delivery process. These include the starting plasmid DNA concentration and the magnitude and duration of the electric field. With regard to the former, plasmid DNA is typically delivered to cells in unitary $\mu \mathrm{g} / \mu$ l concentrations (viscosity becoming a limiting feature with concentrations greater than $\sim 3 \mu \mathrm{g} / \mu \mathrm{l}$, usually in a dilute buffered saline solution). Electric pulse parameters used for gene delivery are typically hundreds of volts for tens of milliseconds, to generate voltage gradients (electric fields) that are in the range of $300-1000$ $\mathrm{V} / \mathrm{cm}(30-100 \mathrm{mV} / \mu \mathrm{m})$ (Rosazza et al., 2016b). The requirement for these high voltages for conventional open-field electroporation can result in potential tissue damage due to local ohmic heating and irreversible dielectric breakdown (Lacković et al., 2009).

\subsection{Validation of $\mathrm{BaDGE}{ }^{\circledR}$ for in vitro and in vivo directed gene delivery}

While conventional open-field electroporation has been employed for in vitro gene delivery to the inner ear as noted above, cochlear implant electrode array - based DNA electrotransfer has been developed for in vivo applications. This platform, being developed out of UNSW Sydney under the trademark BaDGE® ('Bionic array Directed Gene Electrotransfer'), stems from modification of the cochlear implant electrode array, via parallel connection of gangs of electrodes, to create a highly focused electric field enabling close-field electroporation (Pinyon et al., 2014). This provides efficient gene electrotransfer at significantly lower voltages than that required for conventional electroporation. For example, in contrast to the high voltages required for open-field electroporation (above), Fig. 2C of 
Pinyon et al., 2014 indicates thresholds of $<10 \mathrm{~V}$ applied to the cochlear implant array electrodes wired in a 'tandem' configuration; the relationship of voltages, currents and charge transfer used for close-field electroporation against achieved GFP reporter expression in the guinea pig cochlea are evaluated in supplementary information Table S1 in that study. It is significant that the GFP-positive mecenchymal cell counts at threshold, while inherently undersampling the actual number in decalcified whole-mounts of regions of the cochlea, are in the tens of cells, and higher voltages achieve many hundreds of cells, which none-the-less represent a more physiologically relevant mechanism for restoring focal neurotrophin expression to the cochlea than the broad transduction inherent to viral vector-based gene delivery. The anatomy of the cochlea also lends itself to this application, as perfusion of the perilymphatic space achieves uniformity of the naked DNA concentration. For example, in initial ex vivo and in vivo experiments in guinea pigs, buffered plasmid DNA solution was delivered via a tube sealed to the perforated round window, flushing the perilymph out through the perforated oval window membrane of scala vestibuli (via the apically-located helicotrema connection) (Pinyon et al., 2014). Further refinement to include a lumen within the gene delivery array would enable the DNA solution to leave from the tip and flow back along the array to exit via the round window. The proof of concept experiments demonstrated take-up of plasmid DNA encoding BDNF by the mesenchymal (mesothelial) cells lining the perilymphatic compartment of the cochlea. In doing so, the production of recombinant neurotrophins by a relatively small group of these mescenchymal cells was shown to stimulate outgrowth of the auditory nerve fibres into close proximity with the cochlear implant electrodes, thereby closing the neural gap and functionally improving the interface with the cochlear implant array as anticipated (Browne et al., 2016; Housley et al., 2016; Pinyon et al., 2018; Pinyon et al., 2014).

With respect to the constrained geometry of the cochlear structure, the establishment of electric fields for therapeutic DNA electrotransfer in vivo using conventional open-field electroporation is impracticable, both with respect to electrode placement, and also the associated high charge delivery in close proximity to the organ of Corti and spiral ganglion (Fig. 1). A key factor for gene delivery to the cochlea is the consideration of the complex compartmentalization and complex differentiation of the tissue within a very small overall tissue volume, encased within the temporal bone. For example, in the guinea pig and humans, the volume of the scala tympani, are just $4.8 \mu 1$ and $29.2 \mu 1$ respectively (Thorne et al., 1999).

Cochlear implant array - based DNA electrotransfer is based on control of the current paths between multiple electrodes. Early experiments using in situ - ex vivo electrode arraybased DNA electrotransfer in guinea pig cochlea with DNA encoding fluorescent reporters 

efficiency of this process. Neither use of pairs of adjacent platinum ring electrodes $(\sim 350 \mu \mathrm{m}$ diameter x $350 \mu \mathrm{m}$ width), nor use of multiple electrodes in alternating anode and cathode configuration, was as efficient as the ganged wiring of multiple adjacent electrodes in a linear orientation, into distributed anodes and cathodes (designated 'tandem' configuration). Subsequent in vivo guinea pig cochlea green fluorescent protein (GFP) reporter DNA electrotransfer studies (Fig. 3B, Fig. 4) confirmed the efficacy of this tandem electrode configuration (Browne et al., 2016; Pinyon et al., 2014) (Fig. 3B, C; Fig. 4).

Local production of BDNF by the mesenchymal cells was confirmed by immunofluorescence detecting the FLAG-tag incorporated in the pShuttle-CMVp-BDNFflagIRES-GFPnls expression cassette (Fig. 5). Ex vivo experiments confirming the localized BDNF production progressed to in vivo studies in an ototoxic deafened guinea pig, using an intravenous (i.v.) furosemide and subcutaneous (s.c.) kanamycin treatment, followed by a two week period that established hair cell loss and regression of the auditory nerve fibres within the osseous spiral lamina model ((Pinyon et al., 2014); including supplementary material). The cochlear implant array - based DNA electrotransfer BDNF gene augmentation treatment was then provided unilaterally and strong nerve fibre regeneration was observed from around one week post DNA delivery (Fig. 6). This re-growth of the auditory nerve fibres persisted for several weeks beyond when episomal BDNF-encoding plasmid expression ceased (based on detection of GFP fluorescence in the target mescenchymal cells lining scala tympani). A key finding was that the regenerated neurites migrated through the osseous spiral lamina, or in some cases, extended via the canaliculeae perforantes (small pores) of the cochlear modiolar wall, to end with discrete ectopic terminal sprouting within scala tympani. This was aided by the scaffolding that was provided by the fibrosis that arises as an inflammatory response to the cochlear implant array insertion. The local termination of the regenerated processes was ideal in that no lateral extension of the afferents was apparent, and hence the tonotopic representation of the radial fibres is likely to be maintained. These findings provide significant indicators of safety and efficacy of cochlear implant array - based DNA electrotransfer. While the discrete electrotransfer pulse train was at voltages that exceeded the charge transfer limits for the Pt electrodes, such upper charge limits were established for continuous stimulation via cochlear implants. Further, recent studies have shown that cochlear tissues are robust, even when higher than normal charge transfers are delivered continuously via cochlear implants (Shepherd et al., 2018). In the cochlear implant array - based DNA electrotransfer studies, there was no evident tissue injury in the cochlea based on histology and the target mesenchymal cells were vital and 
expressed the plasmid DNA gene cassettes to levels that were physiologically relevant with respect to driving spiral ganglion nerve regeneration via production of BDNF, or indeed expression of a range of reporter genes.

The functional efficacy of BDNF- cochlear implant array - based DNA electrotransfer treatment to enhance the bionic interface was confirmed using electrically-evoked auditory brainstem response (eABR) measurements in guinea-pigs with chronic cochlear implants, using bipolar stimulation via the implant (Fig. 7). The differential between the significantly lower eABR thresholds following the gene augmentation treatment and a control group where a GFP reporter plasmid was maintained out to one month (Fig. 8) with sustained heightened input-output functions reflecting greatly improved progressive neural recruitment (dynamic range) (Pinyon et al., 2014). This proof of principle to enhance cochlear implant performance paves the way for a regulatory permissive use of $\mathrm{BaDGE}^{\circledR}$ for cochlear therapeutics and in particular, use of localized BDNF expression at low levels, to 'close the neural gap' with cochlear implant arrays, which potentially could reduce current stimulation levels (reducing power consumption) and improve the electrode placement discrimination (resulting in better pitch perception). This is supported by the finding that lowered stimulus thresholds with cochlear implant stimulation in deafened cats following neurotrophin treatment to regenerate the auditory nerve fibres, was associated with narrowing of spatial tuning curves in the inferior colliculus (Landry et al., 2013). The potential benefits of an enhanced neural interface for cochlear implant systems will be assessed by translationally focused studies, and an initial phase I/II clinical trial to evaluate the potential of this novel DNA therapeutics technology.

\subsection{Modelling array-based electric field focusing for naked DNA electrotransfer}

The underlying mechanism for the efficiency of bionic array directed gene electrotransfer, has been established in GFP reporter plasmid DNA electrotransfer experiments using adherent HEK293 cells on coverslips as the "target tissue", overlaid by an eight node cochlear implant array. Here it was shown that the tandem gene delivery array configuration caused a substantial compression of the electric field centre around the null between the ganged anodes and cathodes. As such, the absolute voltage in the solution in this zone was found to be very low relative to other regions around the array, but the local voltage differential (change in voltage over distance = electric field strength) was found to be equivalent to fields requiring many hundreds of volts under conventional open-field electroporation where the tissue was located between a pair of electrodes (Browne et al., 2016). This has been modelled (Fig. 9) and the electric field map around the bionic array correlates closely with the bioreporter mapping 

monolayers (Fig. 10). Array-based electric field focusing therefore enables local directed DNA transfer into the cochlea using significantly lower charge delivery and hence is intrinsically less likely to cause tissue damage. This principal is also evidently applicable to other applications where DNA payload titration and localized targeting of DNA-based therapeutics is advantageous.

Based on the efficiency of bionic array - based gene electrotransfer, and this modelling of electric fields, the question arises as to whether contemporary cochlear implant devices may have the intrinsic capability for naked DNA gene electrotransfer at charge transfer levels not much greater than the current upper limits for cochlear implant devices. This does not seem likely, given the rail voltage of cochlear implant devices is $\sim 10 \mathrm{~V}$ to generate a maximum constant current output of $\sim 1 \mathrm{~mA}$, limited to a few tens of $\mu$ s per pulse. Not only is the electric field at, or below, the threshold for gene electrotransfer $(\sim 1 \mathrm{mV} / \mu \mathrm{m}$ (Briaire et al., 2000)), but it is evident from our evaluation of pulse duration, that at such low effective field strengths, pulse durations of many tens of milliseconds is required for gene electrotransfer (Browne et al., 2016), which is not possible using the inductive power transfer modality of cochlear implants. Future generations of cochlear implants may well be designed to incorporate gene electrotransfer modalities, depending upon the findings of the initial clinical trials which require stand-alone systems using a dual array insertion protocol.

With regard to potential tissue injury from the electric pulses used for DNA electrotransfer, conventional 'open-field' electroporation is known to produce both reversible and none-reversible (cell death-causing) cell permeability. In addition, when voltages applied to the electrodes exceed the Faradaic capacity, which for Pt/Ir electrodes occurs at voltages above $\sim 2.8 \mathrm{~V}$, then gassing occurs which affects $\mathrm{pH}$ and causes $\mathrm{Cl}_{2}$ production, both of which impact on cell viability. In the context of cochlear implant - based gene electrotransfer, this is balanced against the fact that typically less than 10 electric monopolar electric pulses are used, whereas the lower amplitude current pulses used for cochlear nerve stimulation by cochlear implants are balanced but continuous and at kHz frequency. Clearly, the development of safe gene electrotransfer into the cochlea will require studies that identify the minimal charge transfer required to safely achieve consistent numbers of transfected mesenchymal cells to produce physiologically relevant neurotrophin levels. This is evidently achievable based on the lack of histopathology associated with the region of transduced mesenchymal cells in the animal gene electrotransfer studies. 


\subsection{Extension of cochlear bionic array directed gene electrotransfer towards clinical trial}

A key aspect of clinical translation of DNA electrotransfer-based therapeutics is the use of plasmids that lack antibiotic resistance genes (European_Medicines_Agency, 2008; European_Medicines_Agency, 2015; FDA, 1998; FDA, 2007). The rationale for this is that DNA electrotransfer could potentially drive expression of conventional plasmid DNA that incorporate antibiotic resistance selection genes in commensual bacteria within the surgical field. To this end, plasmids are being re-engineered to facilitate the translational pathway for this gene therapy modality. We are utilizing a pFAR4 plasmid (version 4 of a 'plasmid Free of Antibiotic Resistance') developed by co-authors Daniel Scherman and Corinne Marie at Descartes University, Paris. The pFAR4 plasmid backbone will also be used in a clinical trial for a gene electrotransfer-based treatment for macular degeneration (Thumann et al., 2017). As a pre-clinical workup to a bionic array directed gene electrotransfer - based cochlear neurotrophin gene therapy application, we undertook control studies using a GFP reporter expression cassette under a CMV promoter on the pFAR4 miniplasmid backbone. The pFAR4CMVp-GFP DNA is significantly smaller than conventional plasmids (1130 bp backbone), as it omits the typical antibiotic resistance expression cassette, and selection is mediated by a (small) suppressor t-RNA motif that restores functional thymidylate synthase (ThyA) to a proprietary Eschericha coli cell line where thyA is mutated (Marie et al., 2010). The smaller size of pFAR4 is thought to improve gene transfer efficiency (Bloquel et al., 2004). These experiments confirmed the effectiveness of the pFAR4 plasmid for cochlear implant array directed gene electrotransfer (Fig. 11). Confocal imaging revealed the GFP reporter signal was confined to mesenchymal cells lining both scala tympani and scala vestibuli in the basal turn of the cochlea. This included prominent labelling of Reissner's membrane, which is integral to the cochlear partition isolating scala media. There was no reporter expression in the three more apical turns, even though the reporter DNA solution was perfused throughout all four turns. This is indicative of the localized gene electrotransfer produced by the bionic array in a 'tandem' configuration of ganged anodes and cathodes. Thus, a key safety feature of bionic array directed DNA electrotransfer is that the biologically active zone for expression of the recombinant proteins is determined by the electric field focusing (electrode configuration and electric pulse parameters). The naked plasmid DNA outside of the electrotransfer zone (both scala tympani and scala vestibuli were perfused) is biologically inert and is subject to degradation by nucleases. For clinical trials, the pFAR4 plasmid backbone can be engineered to incorporate a humanized neurotrophin expression cassette. Delivery of the plasmid DNA could ideally be confined to scala tympani by pumping the DNA solution out of the tip of the 
gene electrotransfer array via incorporation of a lumen through the core of the array. This would enhance the targeting of neurotrophin production, and hence directional cues for spiral ganglion neurite extension towards the subsequently inserted permanent cochlear implant array.

Based on these findings, bionic array directed gene electrotransfer is well positioned for adoption as a means for neurotrophin gene augmentation during cochlear implant surgery. In such a procedure, an otologist would temporarily insert a gene delivery array with integrated delivery of neurotrophin-encoding DNA (BDNF and NT-3). The array would have the same mechanical characteristics as the standard arrays used clinically, to avoid damaging the tissues. Immediately after sufficient DNA solution has been injected from the tip of the array (to flow back out through the perforated round window membrane, or cochleostomy), the gene electrotransfer would be undertaken by passing electric pulses across the electrode array. Gene electrotransfer has been shown to be effectively instantaneous (Escoffre et al., 2011), and in the cochlear implant application, the gene delivery array could be removed immediately - as a disposable item and the routine cochlear implant procedure would resume with implantation of the device of choice. The expression of neurotrophins within hours of the procedure may well enhance survival of the spiral ganglion neurons in the face of the trauma of the surgical procedure (Bas et al., 2015). Peak expression of the BDNF plasmid DNA occurs within a few days, promoting rapid regrowth of the spiral ganglion neurites within the osseous spiral lamina and towards the neurotrophin-expressing mesenchymal cells, thereby reducing the neural-gap with the bionic interface. The caveats to this are the unknowns related to the potential for spiral ganglion neurite regeneration in human subjects who have had sensorineural hearing loss for many years. Temporal bone studies have shown significant retention of spiral ganglion neurons, particularly in the more apical regions of the cochlea, and given the success of cochlear implant treatment in the elderly, this is clearly compatible with neurotrophin-based auditory nerve regeneration strategies (Nadol, 1997). It is unclear whether the osseous spiral lamina will support the outgrowth of the radial fibres in the manner seen with the preclinical acute deafness induced in guinea pigs, but histological analysis of cochleae from elderly subjects demonstrates surprising patency (Glueckert et al., 2005), and in addition, alternative pathways for outgrowth of fibres towards the cochlear implant electrodes, such as via the canaliculae perforantes (Shepherd et al., 2004) were evident in the bionic array directed gene electrotransfer guinea pig cochlea studies (Pinyon et al., 2014).

Central to the safety and efficacy of gene therapy is regulation of expression. While conditionally-regulated gene constructs are routine practice in animal models, such as the use 

switches are problematic for human trials, and considerable research development is on-going around such platforms to support viral vector-based gene therapy applications (for example "RheoSwitch Therapeutic system ${ }^{\circledR} /$ RTS $^{\circledR} "$ (Barrett et al., 2018)). At one end of the spectrum, in the case of an adverse reaction to the treatment, a mechanism for terminating the action is highly desirable, while the ability to control the level of expression of the recombinant protein, and limit action to the target site, are clear aspirations of the field. In the cochlear implant neurotrophin gene augmentation application, control of BDNF in terms of location, level and duration of expression therefore need to be considered. It is known that a range of neurotrophic factors, including BDNF are upregulated in vestibular schwannomas (acoustic neuroma) (Kramer et al., 2010) and likely promote metastatic progression. Clearly existence of such a tumor would be an exclusion criteria for any future cochlear implant-associated neurotrophin clinical trial. As noted above, over-expression of GDNF via AAV5 vector delivery to the cochlea leads to off-target pathology in the CNS in a mouse model (Akil et al., 2018).

The expression profile of neurotrophins in the cochlea driven by bionic array directed gene electrotransfer is likely to be influenced by the nature of the promoter and the plasmid backbone, as well as the underlying fate of the target mesenchymal cells. This was explored in a study that incorporated dual plasmid reporter expression (two plasmid DNAs delivered as 1:1 mix), both in the bionic array directed gene electrotransfer HEK293 cell monolayer model and in the cochleae of normal hearing guinea-pigs (Pinyon et al., 2018). This study had a number of key findings. Central to clinical translation, the fate of the transfected target cells was followed by analysis of the ratio of red (mCherry):green (GFP) fluorescent reporter proteins from the dual plasmid electrotransfer. In the HEK293 cell monolayer model, the ratio of yellow-fluorescence (colocalized expression of red:green reporter coding plasmids) dropped off across the days and weeks following the bionic array directed gene electrotransfer procedure, which was directly related to cell division -based dilution of episomal expression of the many tens of functional copies of the plasmids achieved by electrotransfer, while the number of cells expressing either red or green fluorescence reporter proteins was sustained; indicative of stable single-copy expression. However, in the guinea-pig cochlea bionic array directed gene electrotransfer experiments, the ratios of red:green:yellow fluorescence of the target perilymphatic compartment mesenchymal cells was stable at $\sim 50 \%$, but expression declined to zero by the end of the three week monitoring period. This most likely reflects the fact that mesenchymal cells are terminally differentiated and are turning over with time, with replacement cells derived from precursor cells that were not transfected by bionic array directed 
gene electrotransfer (Pinyon et al., 2018). This is also consistent with the observation in the original experiments (Pinyon et al., 2014), where the limit of detection of GFP reporter expression was $\sim 6$ weeks, with no detectable expression at 10 weeks. Therefore in this application, recombinant neurotrophin expression is likely to be limited in the spatiotemporal domains, with limited numbers of cells of finite duration, as distinct from the situation where viral vectors drive sustained episomal expression in neurons, which have an indefinite lifespan.

In the context of the potential use of the pFAR4 miniplasmid for cochlear neurotrophin gene augmentation, it is notable that while pFAR4 has been shown to provide sustained expression in liver for more than six months, potentially attributable to the minimization of bacterial DNA sequence which tends to induce gene silencing (Quiviger et al., 2014; Quiviger et al., 2018), mesenchymal cell turnover is likely to be the key determining factor for recombinant BDNF production. Given the limitations to gene expression with cochlear implant array-based DNA electrotransfer as developed for neurotrophin gene augmentation, this raises the question of whether the auditory nerve fibre regeneration is sustainable. The original study (Pinyon et al., 2014) showed maintained functional improvement at one month - post DNA electrotransfer in the deafened guinea pig model (see Fig. 8) and some myelinated fibres were detectable within the basal turn scala tyampani region out to ten weeks, albeit in a highly diminished density compared with two to three weeks post-electrotransfer. It is anticipated that in clinical applications, or pre-clinical models such as the deafened cat, where electrical stimulation is provided to the regenerated nerve fibres by chronic use of the cochlear implant, trophic action of the electrical stimulation may sustain the improved neural interface. There is strong experimental evidence for this, based on deafened guinea pig and deafened cat studies where auditory nerve fibre regeneration has been driven by BDNF treatment and spiral ganglion neuron survival and nerve fibre density has been shown to be maintained after cessation of BDNF when electrical stimulation by the cochlear implant is enabled (Landry et al., 2013; Leake et al., 2013; Pettingill et al., 2011; Shepherd et al., 2008). Thus temporary cessation of use of the cochlear implant offers a means to 'reset' the spiral ganglion neuron phenotype, should the neurotrophin gene therapy produce an unanticipated adverse effect on hearing performance, such as a reduction in $\mathrm{CNC}$ word scores over time, where an improvement is typical.

The progression to clinical trials for bionic array directed gene electrotransfer - based neurotrophin gene augmentation in the cochlea would broadly advance directed gene delivery technology, provide new knowledge on the effects of recombinant neurotrophins in the inner ear, and establish the multi-disciplinary expertise and regulatory pathway framework needed 


\section{Funding}

Supported by funding from the Australian Research Council (ARC), grants (ARC DP151014754, ARC LP0992098, ARC LP140101008), the Garnett Passe and Rodney Williams Memorial Foundation, and the National Health and Medical Research Council (NHMRC) grants APP1091646, APP1122055 and GNT1142910. The research was supported by collaborative research funding from Cochlear Ltd.

\section{Declaration of interest}

The $\mathrm{BaDGE}^{\circledR}$ registered trademark is assigned to UNSW Sydney Knowledge Exchange though New South Innovations Pty Ltd, which is also the assignee for the BaDGE ${ }^{\circledR}$-related intellectual property. 
Akil, O., Blits, B., Lustig, L.R., Leake, P.A. 2018. Virally Mediated Overexpression of GlialDerived Neurotrophic Factor Elicits Age- and Dose-Dependent Neuronal Toxicity and Hearing Loss. Hum Gene Ther.

Akil, O., Seal, R.P., Burke, K., Wang, C., Alemi, A., During, M., Edwards, R.H., Lustig, L.R. 2012. Restoration of hearing in the VGLUT3 knockout mouse using virally mediated gene therapy. Neuron 75, 283-93.

Baker, K., Brough, D.E., Staecker, H. 2009. Repair of the vestibular system via adenovector delivery of Atoh1: a potential treatment for balance disorders. Adv Otorhinolaryngol 66, 52-63.

Barrett, J.A., Cai, H., Miao, J., Khare, P.D., Gonzalez, P., Dalsing-Hernandez, J., Sharma, G., Chan, T., Cooper, L.J.N., Lebel, F. 2018. Regulated intratumoral expression of IL-12 using a RheoSwitch Therapeutic System $((\mathrm{R}))(\mathrm{RTS}((\mathrm{R})))$ gene switch as gene therapy for the treatment of glioma. Cancer Gene Ther 25, 106-116.

Bas, E., Goncalves, S., Adams, M., Dinh, C.T., Bas, J.M., Van De Water, T.R., Eshraghi, A.A. 2015. Spiral ganglion cells and macrophages initiate neuro-inflammation and scarring following cochlear implantation. Front Cell Neurosci 9, 303.

Belyantseva, I.A. 2009. Helios Gene Gun-mediated transfection of the inner ear sensory epithelium. Methods Mol Biol 493, 103-23.

Bloquel, C., Fabre, E., Bureau, M.F., Scherman, D. 2004. Plasmid DNA electrotransfer for intracellular and secreted proteins expression: new methodological developments and applications. J Gene Med 6 Suppl 1, S11-23.

Briaire, J.J., Frijns, J.H. 2000. Field patterns in a 3D tapered spiral model of the electrically stimulated cochlea. Hear Res 148, 18-30.

Brough, D.E., Ettyreddy, D.R. 2016. Adenoviral vector encoding human atonal homolog-1 (HATH1). In: Organization, W.I.P., (Ed.). Genvec, Inc.

Browne, C.J., Pinyon, J.L., Housley, D.M., Crawford, E.N., Lovell, N.H., Klugmann, M., Housley, G.D. 2016. Mapping of bionic array electric field focusing in plasmid DNAbased gene electrotransfer. Gene Ther 23, 369-79.

Budenz, C.L., Pfingst, B.E., Raphael, Y. 2012. The use of neurotrophin therapy in the inner ear to augment cochlear implantation outcomes. Anat Rec (Hoboken) 295, 1896-908.

Driver, E.C., Kelley, M.W. 2010. Transfection of mouse cochlear explants by electroporation. Curr Protoc Neurosci Chapter 4, Unit 434 1-10.

Escoffre, J.M., Portet, T., Favard, C., Teissie, J., Dean, D.S., Rols, M.P. 2011. Electromediated formation of DNA complexes with cell membranes and its consequences for gene delivery. Biochim Biophys Acta 1808, 1538-43.

European_Medicines_Agency. 2008. Guideline on the non-clinical studies required before first clinical use of gene therapy medicinal products.

EMEA/CHMP/GTWP/125459/2006, 10.

European_Medicines_Agency. 2015. Guideline on the quality, non-clinical and clinical aspects 4 of gene therapy medicinal products. EMA/CAT/80183/2014, 42.

FDA. 1998. Guidance for Industry: Guidance for Human Somatic Cell and Gene Therapy.

FDA. 2007. Guidance for Industry: Considerations for plasmid DNA Vaccines for Infectious Disease.

Fransson, A., Ulfendahl, M. 2017. Structural changes in the inner ear over time studied in the experimentally deafened guinea pig. J Neurosci Res 95, 869-875. 
Fransson, A., Tornoe, J., Wahlberg, L.U., Ulfendahl, M. 2018. The feasibility of an encapsulated cell approach in an animal deafness model. J Control Release 270, 275281.

Glueckert, R., Pfaller, K., Kinnefors, A., Rask-Andersen, H., Schrott-Fischer, A. 2005. The human spiral ganglion: new insights into ultrastructure, survival rate and implications for cochlear implants. Audiol Neurootol 10, 258-73.

Hendricks, J.L., Chikar, J.A., Crumling, M.A., Raphael, Y., Martin, D.C. 2008. Localized cell and drug delivery for auditory prostheses. Hear Res 242, 117-31.

Housley, G.D., Browne, C.J., Crawford, E.N., Klugmann, M., Lovell, N.H., Pinyon, J.L. 2016. Cochlear Implant Close-Field Electroporation. In: Miklavčič, D., (Ed.), Handbook of Electroporation. Springer. pp. 1-20. DOI 10.1007/978-3-319-267791 59-1.

Husseman, J., Raphael, Y. 2009. Gene therapy in the inner ear using adenovirus vectors. Adv Otorhinolaryngol 66, 37-51.

Izumikawa, M., Minoda, R., Kawamoto, K., Abrashkin, K.A., Swiderski, D.L., Dolan, D.F., Brough, D.E., Raphael, Y. 2005. Auditory hair cell replacement and hearing improvement by Atoh1 gene therapy in deaf mammals. Nat Med 11, 271-6.

Kamakura, T., Nadol, J.B., Jr. 2016. Correlation between word recognition score and intracochlear new bone and fibrous tissue after cochlear implantation in the human. Hear Res 339, 132-41.

Kawamoto, K., Ishimoto, S., Minoda, R., Brough, D.E., Raphael, Y. 2003. Math1 gene transfer generates new cochlear hair cells in mature guinea pigs in vivo. J Neurosci 23, 4395-400.

Kelley, M.W. 1997. Cellular commitment and differentiation in the cochlea: potential advances using gene transfer. Audiol Neurootol 2, 50-60.

Kramer, F., Stover, T., Warnecke, A., Diensthuber, M., Lenarz, T., Wissel, K. 2010. BDNF mRNA expression is significantly upregulated in vestibular schwannomas and correlates with proliferative activity. J Neurooncol 98, 31-9.

Lacković, I., Magjarević, R., D., M. 2009. Three-dimensional finite-element analysis of joule heating in electrochemotherapy and in vivo gene electrotransfer. IEEE Transactions on Dielectrics and Electrical Insulation 16, 1338 - 1347.

Landegger, L.D., Pan, B., Askew, C., Wassmer, S.J., Gluck, S.D., Galvin, A., Taylor, R., Forge, A., Stankovic, K.M., Holt, J.R., Vandenberghe, L.H. 2017. A synthetic AAV vector enables safe and efficient gene transfer to the mammalian inner ear. Nat Biotechnol 35, 280-284.

Landry, T.G., Fallon, J.B., Wise, A.K., Shepherd, R.K. 2013. Chronic neurotrophin delivery promotes ectopic neurite growth from the spiral ganglion of deafened cochleae without compromising the spatial selectivity ofcochlear implants. The Journal of comparative neurology.

Leake, P.A., Hradek, G.T., Rebscher, S.J., Snyder, R.L. 1991. Chronic intracochlear electrical stimulation induces selective survival of spiral ganglion neurons in neonatally deafened cats. Hear Res 54, 251-71.

Leake, P.A., Stakhovskaya, O., Hetherington, A., Rebscher, S.J., Bonham, B. 2013. Effects of brain-derived neurotrophic factor (BDNF) and electrical stimulation on survival and function of cochlear spiral ganglion neurons in deafened, developing cats. J Assoc Res Otolaryngol 14, 187-211.

Li, Y., Jia, Y.C., Cui, K., Li, N., Zheng, Z.Y., Wang, Y.Z., Yuan, X.B. 2005. Essential role of TRPC channels in the guidance of nerve growth cones by brain-derived neurotrophic factor. Nature 434, 894-8.

Lustig, L.R., Akil, O. 2012. Cochlear gene therapy. Curr Opin Neurol 25, 57-60. 

pFARs, plasmids free of antibiotic resistance markers, display high-level transgene expression in muscle, skin and tumour cells. J Gene Med 12, 323-32.

Metzger, D., Clifford, J., Chiba, H., Chambon, P. 1995. Conditional site-specific recombination in mammalian cells using a ligand-dependent chimeric Cre recombinase. Proceedings of the National Academy of Sciences of the United States of America 92, 6991-5.

Miller, J.M., Le Prell, C.G., Prieskorn, D.M., Wys, N.L., Altschuler, R.A. 2007. Delayed neurotrophin treatment following deafness rescues spiral ganglion cells from death and promotes regrowth of auditory nerve peripheral processes: effects of brainderived neurotrophic factor and fibroblast growth factor. J Neurosci Res 85, 1959-69.

Nadol, J.B., Jr. 1997. Patterns of neural degeneration in the human cochlea and auditory nerve: implications for cochlear implantation. Otolaryngol Head Neck Surg 117, 2208.

Nadol, J.B., Jr., Shiao, J.Y., Burgess, B.J., Ketten, D.R., Eddington, D.K., Gantz, B.J., Kos, I., Montandon, P., Coker, N.J., Roland, J.T., Jr., Shallop, J.K. 2001. Histopathology of cochlear implants in humans. Ann Otol Rhinol Laryngol 110, 883-91.

Pan, B., Geleoc, G.S., Asai, Y., Horwitz, G.C., Kurima, K., Ishikawa, K., Kawashima, Y., Griffith, A.J., Holt, J.R. 2013. TMC1 and TMC2 are components of the mechanotransduction channel in hair cells of the mammalian inner ear. Neuron 79, 504-15.

Pan, B., Askew, C., Galvin, A., Heman-Ackah, S., Asai, Y., Indzhykulian, A.A., Jodelka, F.M., Hastings, M.L., Lentz, J.J., Vandenberghe, L.H., Holt, J.R., Geleoc, G.S. 2017. Gene therapy restores auditory and vestibular function in a mouse model of Usher syndrome type 1c. Nat Biotechnol 35, 264-272.

Pettingill, L.N., Wise, A.K., Geaney, M.S., Shepherd, R.K. 2011. Enhanced auditory neuron survival following cell-based BDNF treatment in the deaf guinea pig. PLoS One 6, e18733.

Phan, P.A., Tadros, S.F., Kim, Y., Birnbaumer, L., Housley, G.D. 2010. Developmental regulation of TRPC3 ion channel expression in the mouse cochlea. Histochem Cell Biol 133, 437-48.

Pharmaceuticals, N. 2019. Safety, Tolerability and Efficacy for CGF166 in Patients With Unilateral or Bilateral Severe-to-profound Hearing Loss. https://clinicaltrials.gov/ct2/show/NCT02132130.

Pinyon, J.L., Klugmann, M., Lovell, N.H., Housley, G.D. 2018. Dual-Plasmid Bionic ArrayDirected Gene Electrotransfer in HEK293 Cells and Cochlear Mesenchymal Cells Probes Transgene Expression and Cell Fate. Hum Gene Ther.

Pinyon, J.L., Tadros, S.F., Froud, K.E., AC, Y.W., Tompson, I.T., Crawford, E.N., Ko, M., Morris, R., Klugmann, M., Housley, G.D. 2014. Close-field electroporation gene delivery using the cochlear implant electrode array enhances the bionic ear (supplementary information). Science Translational Medicine 6 (233), 233ra54. [doi: 10.1126/scitranslmed.3008177].

Praetorius, M., Hsu, C., Baker, K., Brough, D.E., Plinkert, P., Staecker, H. 2010. Adenovector-mediated hair cell regeneration is affected by promoter type. Acta Otolaryngol 130, 215-22.

Quiviger, M., Arfi, A., Mansard, D., Delacotte, L., Pastor, M., Scherman, D., Marie, C. 2014. High and prolonged sulfamidase secretion by the liver of MPS-IIIA mice following hydrodynamic tail vein delivery of antibiotic-free pFAR4 plasmid vector. Gene Ther 21, 1001-7. 

molecular platform for the gene therapy of rare diseases by liver protein secretion. Eur J Med Genet 61, 723-728.

Ramekers, D., Versnel, H., Grolman, W., Klis, S.F. 2012. Neurotrophins and their role in the cochlea. Hear Res 288, 19-33.

Rosazza, C., Meglic, S.H., Zumbusch, A., Rols, M.P., Miklavcic, D. 2016a. Gene Electrotransfer: A Mechanistic Perspective. Curr Gene Ther 16, 98-129.

Rosazza, C., Deschout, H., Buntz, A., Braeckmans, K., Rols, M.P., Zumbusch, A. 2016b. Endocytosis and Endosomal Trafficking of DNA After Gene Electrotransfer In Vitro. Mol Ther Nucleic Acids 5, e286.

Schlecker, C., Praetorius, M., Brough, D.E., Presler, R.G., Jr., Hsu, C., Plinkert, P.K., Staecker, H. 2011. Selective atonal gene delivery improves balance function in a mouse model of vestibular disease. Gene Ther 18, 884-90.

Seyyedi, M., Viana, L.M., Nadol, J.B., Jr. 2014. Within-subject comparison of word recognition and spiral ganglion cell count in bilateral cochlear implant recipients. Otol Neurotol 35, 1446-50.

Shepherd, R.K., Colreavy, M.P. 2004. Surface microstructure of the perilymphatic space: implications for cochlear implants and cell- or drug-based therapies. Arch Otolaryngol Head Neck Surg 130, 518-23.

Shepherd, R.K., Wise, A.K. 2014. Gene therapy boosts the bionic ear. Sci Transl Med 6, $233 \mathrm{fs} 17$.

Shepherd, R.K., Coco, A., Epp, S.B. 2008. Neurotrophins and electrical stimulation for protection and repair of spiral ganglion neurons following sensorineural hearing loss. Hear Res 242, 100-9.

Shepherd, R.K., Carter, P.M., Enke, Y.L., Wise, A.K., Fallon, J.B. 2018. Chronic intracochlear electrical stimulation at high charge densities results in platinum dissolution but not neural loss or functional changes in vivo. J Neural Eng 16, 026009.

Shibata, S.B., Cortez, S.R., Beyer, L.A., Wiler, J.A., Di Polo, A., Pfingst, B.E., Raphael, Y. 2010. Transgenic BDNF induces nerve fiber regrowth into the auditory epithelium in deaf cochleae. Exp Neurol 223, 464-72.

Tadros, S.F., Kim, Y., Phan, P.A., Birnbaumer, L., Housley, G.D. 2010. TRPC3 ion channel subunit immunolocalization in the cochlea. Histochem Cell Biol 133, 137-47.

Thorne, M., Salt, A.N., DeMott, J.E., Henson, M.M., Henson, O.W., Jr., Gewalt, S.L. 1999. Cochlear fluid space dimensions for six species derived from reconstructions of threedimensional magnetic resonance images. Laryngoscope 109, 1661-8.

Thumann, G., Harmening, N., Prat-Souteyrand, C., Marie, C., Pastor, M., Sebe, A., Miskey, C., Hurst, L.D., Diarra, S., Kropp, M., Walter, P., Scherman, D., Ivics, Z., Izsvak, Z., Johnen, S. 2017. Engineering of PEDF-Expressing Primary Pigment Epithelial Cells by the SB Transposon System Delivered by pFAR4 Plasmids. Mol Ther Nucleic Acids 6, 302-314.

Wang, L., Jiang, H., Brigande, J.V. 2012. Gene transfer to the developing mouse inner ear by in vivo electroporation. J Vis Exp.

Wise, A.K., Richardson, R., Hardman, J., Clark, G., O'Leary, S. 2005. Resprouting and survival of guinea pig cochlear neurons in response to the administration of the neurotrophins brain-derived neurotrophic factor and neurotrophin-3. The Journal of comparative neurology 487, 147-65. 
Wise, A.K., Tan, J., Wang, Y., Caruso, F., Shepherd, R.K. 2016. Improved Auditory Nerve Survival with Nanoengineered Supraparticles for Neurotrophin Delivery into the Deafened Cochlea. PLoS One 11, e0164867.

Wise, A.K., Fallon, J.B., Neil, A.J., Pettingill, L.N., Geaney, M.S., Skinner, S.J., Shepherd, R.K. 2011. Combining cell-based therapies and neural prostheses to promote neural survival. Neurotherapeutics 8, 774-87.

Wise, A.K., Hume, C.R., Flynn, B.O., Jeelall, Y.S., Suhr, C.L., Sgro, B.E., O'Leary, S.J., Shepherd, R.K., Richardson, R.T. 2010. Effects of localized neurotrophin gene expression on spiral ganglion neuron resprouting in the deafened cochlea. Mol Ther $18,1111-22$.

Wong, S.P., Argyros, O., Harbottle, R.P. 2015. Sustained expression from DNA vectors. Adv Genet 89, 113-52.

Xiong, W., Wagner, T., Yan, L., Grillet, N., Muller, U. 2014. Using injectoporation to deliver genes to mechanosensory hair cells. Nat Protoc 9, 2438-49.

Zhao, H., Avenarius, M.R., Gillespie, P.G. 2012. Improved biolistic transfection of hair cells. PLoS One 7, e46765. 


\section{Figure Legends}

Fig. 1: Anatomy of the cochlea. A) 3D reconstruction of confocal scans showing the 4 spiraling turns of a hemi-sectioned guinea pig cochlea. The endolymph-filled compartment scala media (SM) is situated between the perilymphatic compartments scala tympani (ST) and scala vestibuli (SV), which meet at the apical helicotrema (H). Reissner's membrane (RM) separates scala media from scala vestibuli, with epithelial cells lining the endolymphatic surface and mesenchymal cells lining the perilymphatic surface. The sound-transducing sensory epithelium (SE) located between scala tympani and scala media is innervated by the spiral ganglion neurons. The cell bodies of these neurons are shown as yellow within Rosenthal's canal (RC). Green labelling is a neuronal-specific antibody (anti- $\beta$ III tubulin) excited by a $488 \mathrm{~nm}$ argon ion laser, red is non-specific tissue autofluorescence excited by a $561 \mathrm{~nm}$ diode pumped solid state laser, showing anatomical structure. B) A single confocal scan showing a close-up view of the sensory epithelium sitting on the basilar membrane (BM). Most of the green spiral ganglion neuron peripheral neurites innervate individual inner hair cells (IHC), with a subset innervating multiple outer hair cells (OHC) within the outer three rows. Blue signal shows the nuclear-specific DAPI stain and red shows a $647 \mathrm{~nm}$-conjugated phalloidin, which specifically binds to the F-actin within stereocilia and cuticular plate regions of the hair cells and the pillar cells. Transmitted light resolving other structure is shown in grey.

Fig. 2: The guinea pig cochlear implant array-based DNA electrotransfer model. A) Image of an isolated and decalcified guinea pig cochlea with an eight-electrode animal model cochlear implant array partially inserted (five of eight electrodes inside). When the cochlea is decalcified, as used in this demonstration, it becomes semi-transparent and thus three of the internal electrodes can be seen behind the outer capsule wall of basal scala tympani. B) MicroCT generated image showing cochlear implant in situ within the skull of a chronically implanted guinea pig. Arrow indicates insertion of the 8 electrode array into the basal turn of the left cochlea.

Fig. 3: Directed gene electrotransfer using the cochlear implant. Epifluorescence images of ressected guinea pig cochleae after array-based electrotransfer using a bicistronic plasmid encoding a nuclear localised GFP reporter along with a BDNF - encoding gene sequence driven by the cytomegalovirus promoter (pShuttle-CMVp-BDNFflag-IRES-GFPnls, after (Pinyon et al., 2014)). The bony outer capsule has been removed, with internal structure mostly still intact. 
Bright white spots represent GFP positive transfected cells emitting green light after excitation with blue light. These cells are located in the basal of the four turns of the cochlea, in close proximity to the electrode array, which could only penetrate that region of scala tympani. A) GP296 - cochlear implant array-based DNA electrotransfer was performed ex vivo and the whole cochlea explant was cultured for 3 days ('alternating' electrode polarity configuration; $20 \times 50 \mathrm{~ms}$ pulses of $40 \mathrm{~V}$ at $1 \mathrm{~Hz}$.). B) GP286 - - cochlear implant array-based DNA electrotransfer was performed in vivo using the same electrotransfer parameters as in (A), with the gene delivery array removed immediately after DNA electrotransfer and the tissue collected 3 days later. C) GP293 - in vivo - cochlear implant array-based DNA electrotransfer as for (B), where the tissue was collected 2 days after gene delivery, showing the localisation of the GFP+ cells in the basal turn, where the gene delivery array was inserted, despite the perfusion of the entire perilymphatic space with the reporter plasmid DNA. Unpubl. images (Pinyon et al., 2014).

Fig. 4: Three-dimensional confocal reconstruction of a guinea pig cochlea transfected with a plasmid DNA encoding a nuclear localized green fluorescent protein reporter via cochlear implant array-based DNA electrotransfer. GFP + cells are located on the basal modiolar wall, the cochlear structure imaged via background autofluorescence is shown in red. (GP276 tandem electrode array configuration, $40 \mathrm{~V}$ x 5 pulses x $50 \mathrm{~ms}$ at $1 \mathrm{~Hz}, 14$ days after in vivo DNA electrotransfer, with the gene delivery array removed immediately). Plasmid: pShuttle-CMVp-BDNFflag-IRES-GFPnls. Unpubl. images (Pinyon et al., 2014).

\section{Fig. 5: Production of recombinant brain-derived neurotrophic factor (BDNF) after gene} electrotransfer using the cochlear implant. Confocal 3D reconstructions of transfected cells expressing the nuclear localised GFP reporter gene (green) fluorescence and BDNF (red). The red signal represents a $594 \mathrm{~nm}$ conjugated antibody after anti-FLAG immunohistochemistry targeted at the FLAG-tagged recombinant BDNF encoded on the delivered plasmid DNA. A) A high magnification view of two cells located on the modiolar wall of basal scala tympani. GP-FB029 tandem $20 \mathrm{~V}$ x 5 pulses x $50 \mathrm{~ms}$ at $1 \mathrm{~Hz}$, five days following DNA electrotransfer, with the gene delivery probe removed immediately. B) BDNF expressing cells on Reissner's membrane in the cochlea basal turn. GP-FB007 alternating $40 \mathrm{~V}$ x 20 pulses x $50 \mathrm{~ms}$ at $1 \mathrm{~Hz}$, two days post ex vivo cochlear implant array-based DNA electrotransfer. Plasmid: pShuttleCMVp-BDNFflag-IRES-GFPnls. Unpubl. images (Pinyon et al., 2014). 
Fig. 6: Neurotrophin-induced cochlear nerve regeneration after Bionic Array Directed Gene Electrotransfer (BADGE). Confocal scans showing $50 \mu \mathrm{m}$ cryosections of cochleae from the left and right sides of deafened guinea pigs where the left cochleae received BADGE of the neurotrophin cassette 2 weeks after deafening (alternating configuration $40 \mathrm{~V}$ x 20 pulses x $50 \mathrm{~ms}$ at $1 \mathrm{~Hz}$ ). A) Left treated cochlea of GP283 showing regeneration of the peripheral neurites of the spiral ganglion neurons in green. B) Right untreated cochlea from the same animal shown in (A). C) A second example of a left treated cochlea from another animal GP284. D) The right control untreated cochlea from the animal in (C). E) A second $50 \mu \mathrm{m}$ cryosection from the left treated cochlea (GP284) also shown in (C). F) A high magnification image of the neurite outgrowth towards the flattened sensory epithelium shown in (E). Arrows point to the regenerated fibres throughout the fibre tracks in the osseous spiral lamina and ectopic branching into both scala tympani (ST) and scala media (SM). Green is neural specific staining (TUJ1) highlighting the nerve cell bodies and fibres. Red is autofluorescence of the bony tissue. Grey represents transmitted light showing cochlear structure. SV; scala vestibuli. Plasmid: pShuttle-CMVp-BDNFflag-IRES-GFPnls. Unpubl. images (Pinyon et al., 2014).

\section{Fig. 7: Enhanced cochlear implant performance after neurotrophin gene}

electrotransfer. A) Acoustically-evoked auditory brainstem responses (ABRs) representative of those in normal hearing guinea pigs, prior to ototoxic treatment, in response to broadband click stimulus (dBSPL). B) Traces from the same animal in (A) recorded one-week after ototoxic treatment. No response was detected up to the maximum tested $90 \mathrm{~dB}$ SPL ( $85 \mathrm{~dB}$ and $90 \mathrm{~dB}$ traces not shown). C) Electrically-evoked auditory brainstem responses (eABRs) in a guinea pig 4 weeks after deafening and 2 weeks post cochlear implantation without neurotrophin gene therapy. D) eABRs in a guinea pig 4 weeks after deafening and 2 weeks post cochlear implantation and neurotrophin gene electrotransfer, showing recovery of neural integrity through reduced thresholds and increased magnitudes of recruitment. eABR used bipolar stimulation between ganged electrodes 1-4 and 5-8, corresponding to the 'tandem' configuration; alternating monophasic constant current pulses of $100 \mu$ s duration (averaged over 512 trials). Neurotrophin gene delivery utilised bionic array -based electrotransfer. Plasmid: pShuttle-CMVp-BDNFflag-IRES-GFPnls. Unpubl. images (Pinyon et al., 2014).

Fig. 8: Lowered eABR thresholds in guinea-pig cochleae treated with a BDNF-encoding plasmid via cochlear implant array - based DNA electrotransfer measured one month after electrotransfer. These data show the maintenance of the improved bionic ear neural 
interface beyond the previously reported two week time point ((Pinyon et al., 2014) Unpubl. data). $\mathrm{n}=5$ for control, $\mathrm{n}=3$ for BNDF gene augmentation. Box plot boundaries show $25 \%$ and $75 \%$ ranges for the control plasmid and upper and lower range for the neurotrophin group, solid line is median, dashed line = mean. Thresholds determined visually as shown in the previous figure. (100 $\mu$ s pulse width). BDNF data plasmid: pShuttle-CMVp-BDNFflag-IRESGFPnls; GFP data plasmid: pShuttle-CMVp-IRES-GFPnls.

Fig. 9: Electric field modelling in silico of bionic array directed gene electrotransfer electric field maps based on an eight node cochlear implant electrode array. Modelling was undertaken based on a $50 \mu \mathrm{l}$ volume of saline (conductivity $1.5 \mathrm{~S} / \mathrm{m}$ ) stimulated with $4 \mathrm{~V}$ pulses using (A) ganged (four anodes (red), + four cathodes (blue) - 'tandem') electrode configuration and (B) 'alternating' polarity. Platinum-iridium electrode diameters $350 \mu \mathrm{m}$, length $300 \mu \mathrm{m}$, inter-electrode spacing $300 \mu \mathrm{m}$ ). Top panels illustrate model geometry and stimulation configuration; In this model $+4 \mathrm{~V}$ and $-4 \mathrm{~V}$ were applied at the anodes and cathodes respectively. Centre panels show the field voltages arsing from the two electrode array configurations, where the null point ( 0 voltage) extends orthogonally from the region between the + and - electrodes, or gangs of electrodes. Bottom panels display contour maps of the calculated electric fields. This highlights the point that it is not the absolute voltage that drives DNA electrotransfer, but the change in voltage over distance (electric field) which is greatest closest to the null points. We propose that cells experiencing electric fields in the $8-80 \mathrm{~V} / \mathrm{cm}$ range will be transfected with DNA. Grey regions indicate the electric field is too weak to achieve electrotransfer.

Fig. 10: Directed gene electrotransfer using HEK293 cell monolayers as a model for cochlear implant array-based electric field focusing. Bionic array directed gene electrotransfer was performed in the HEK393 cell model using the cochlear implant eightelectrode array (shown as an overlay; anodes indicated as red + symbols and cathodes as black - symbols). The cells were grown on a round coverslip. Green spots indicate transfected cells expressing a GFP reporter gene detected using epifluorescence microscopy. Note that the cells are clustered in a circle around the mid-point of the array. This is centred on the null-point of the electric potential, but the highest electric field (greatest differential in field voltage with distance; see Fig. 9). In this example, $+40 \mathrm{~V}$ was applied to the anodes relative to the cathodes ( 5 x 50 ms pulses; Plasmid: pShuttle-CMVp-BDNFflag-IRES-GFPnls, $2 \mu \mathrm{g} / \mu 1$; four day cell culture post - DNA delivery). 
Fig. 11: GFP reporter expression confined to the basal turn region of the guinea pig cochlea after four days expression of the regulatory compliant pFAR4-CMVp-GFP miniplasmid in vivo. The entire perilyphatic space was perfused with the naked DNA solution ( $(2 \mu \mathrm{g} / \mu \mathrm{l}$ plasmid DNA, dissolved in Tris-buffered saline). The cochlear implant electrode array, modified as an acute gene delivery array where the four most internal electrodes acted as ganged anodes and the four basal electrodes as ganged cathodes ('tandem' configuration), was then inserted into scala tympani through the round window membrane (penetrating just the basal turn). A CUY21 electroporator (NepaGene, Japan) delivered $3 \times 100 \mathrm{~ms}$ pulses of 30 $\mathrm{V}$ to achieve the gene electrotransfer. The cochlear implant electrode array was removed immediately after the delivery of the pulse train. The image is a hemi-section view following decalcification of the treated cochlea. Note the green fluorescence signal is confined to the basal turn region where the gene delivery array was positioned. SV - scala vestibuli, ST - scala tympani, RM - Reissner's membrane. 

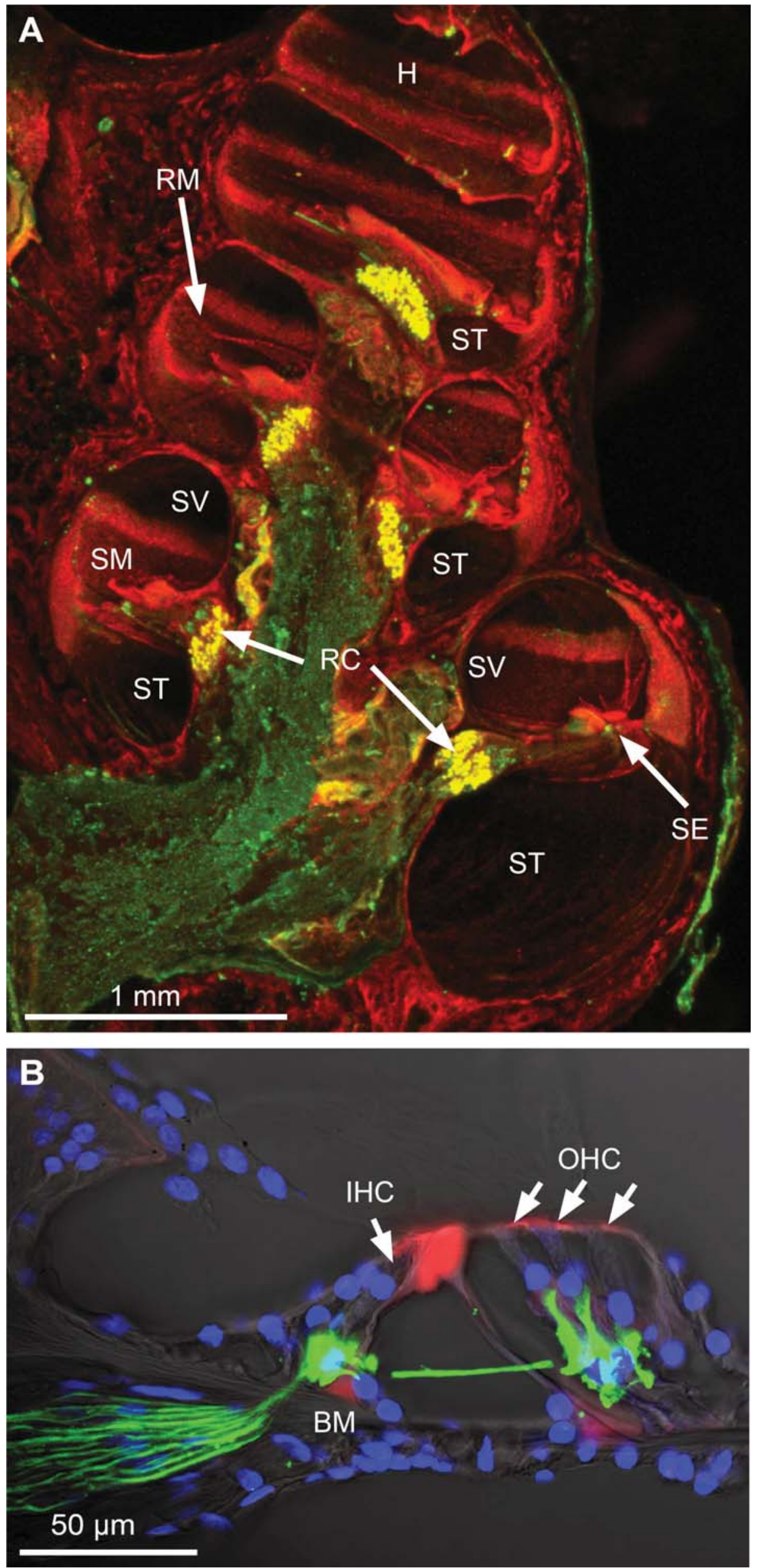

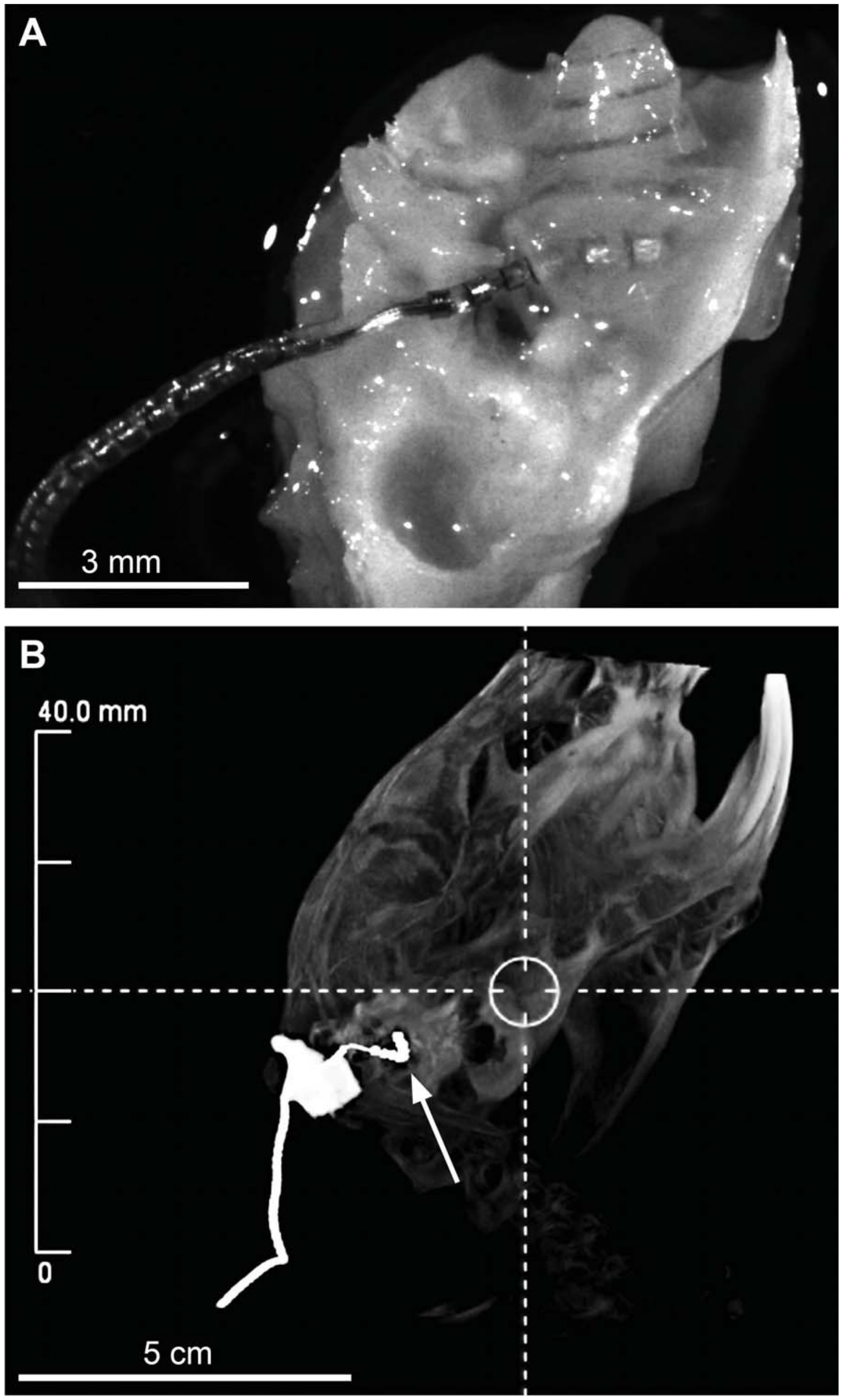

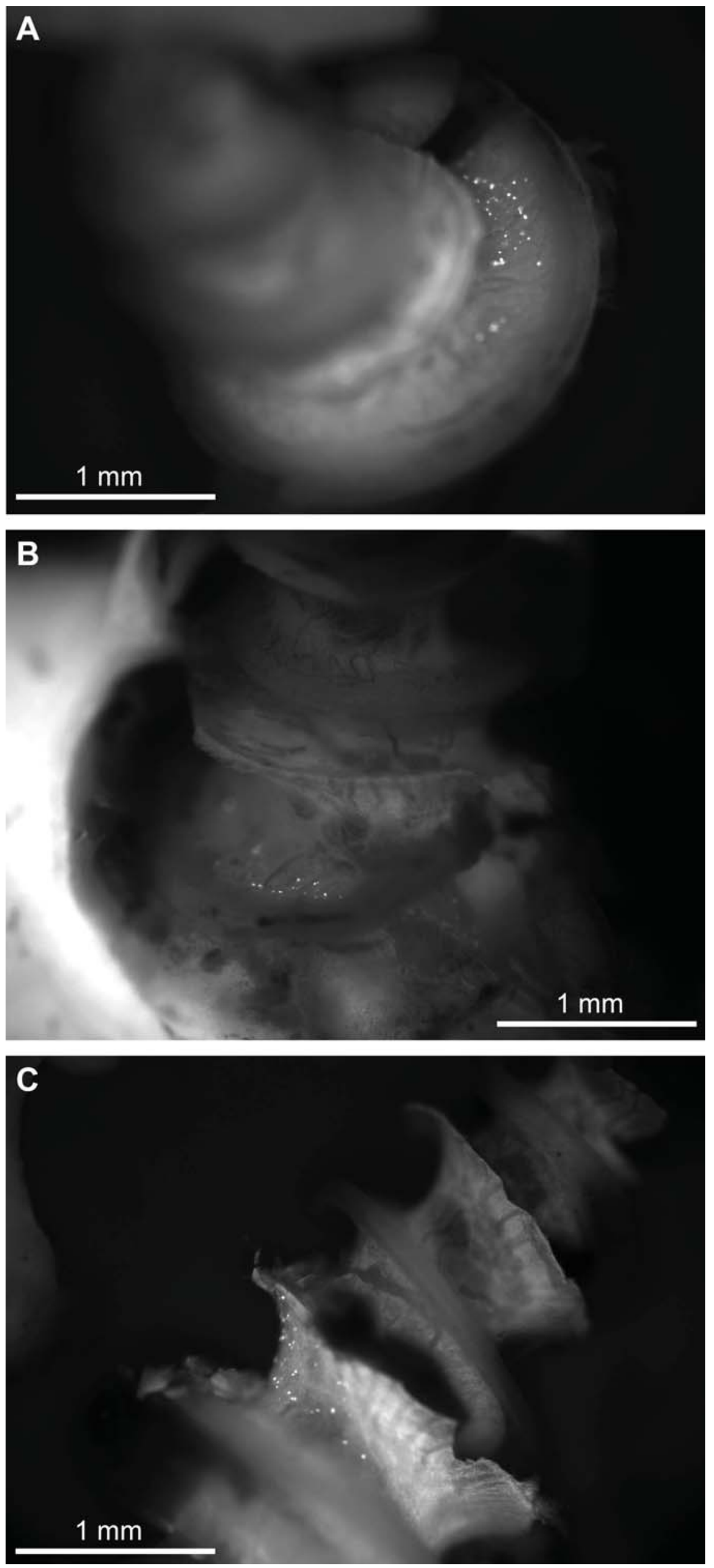


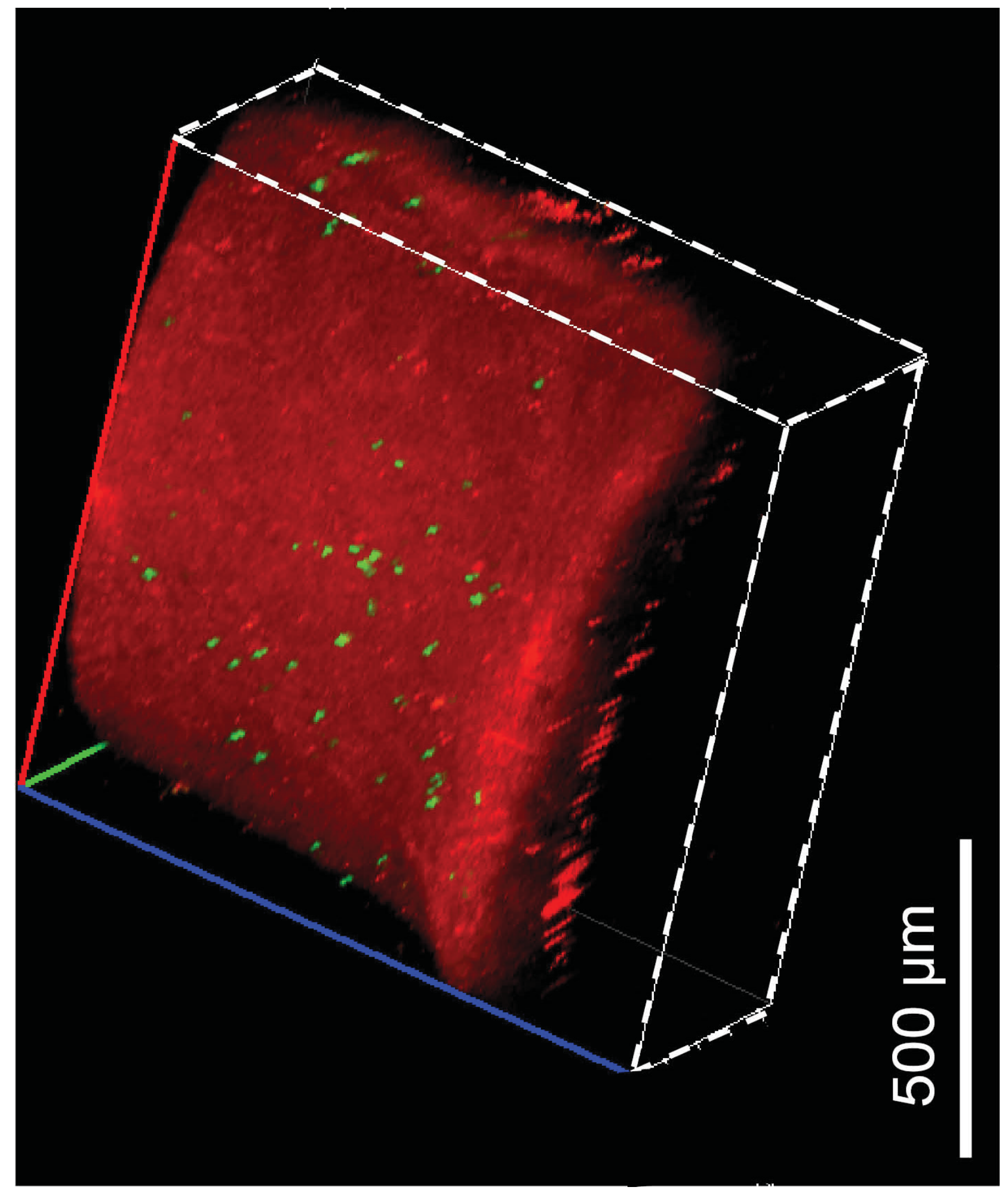



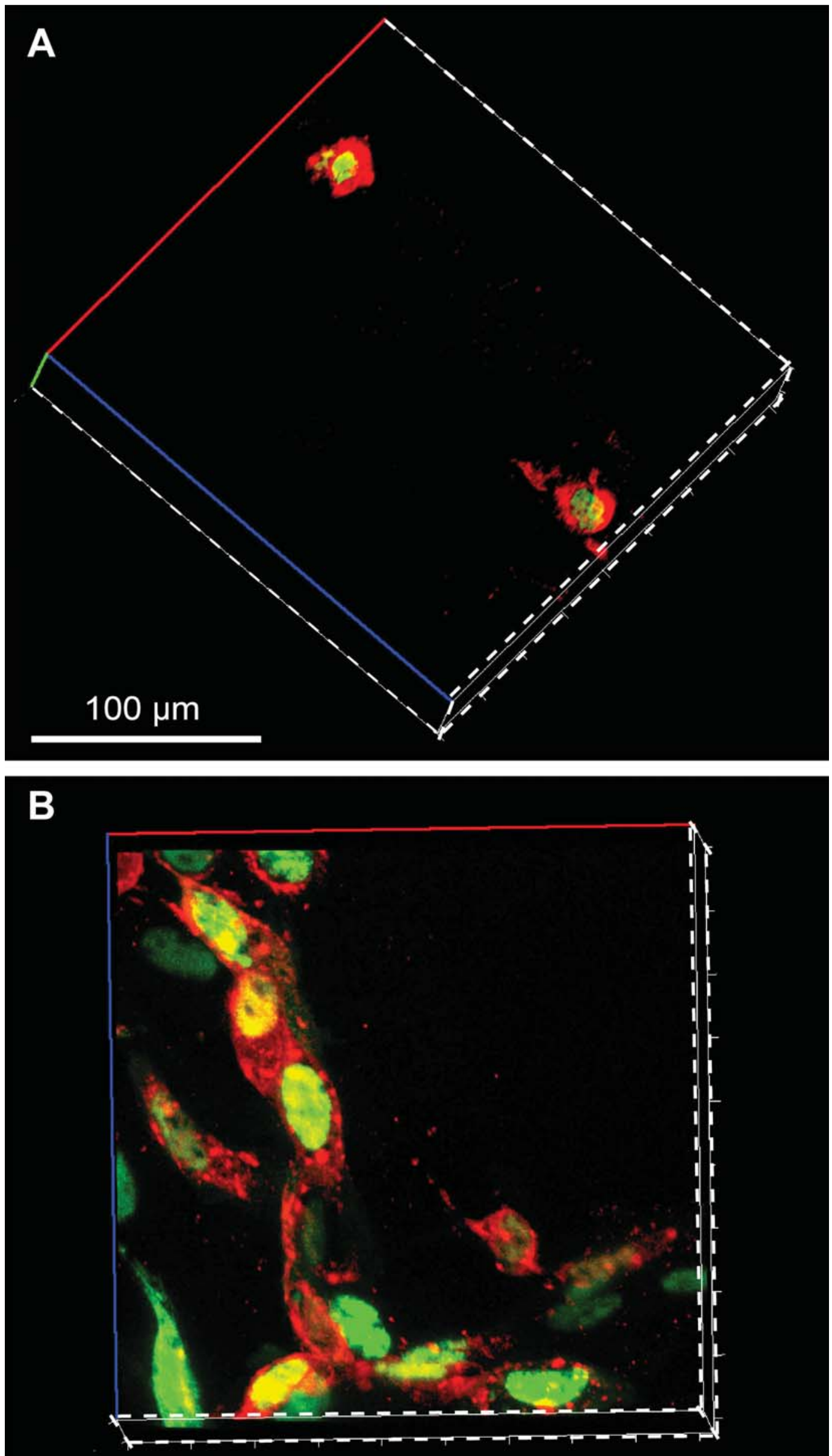


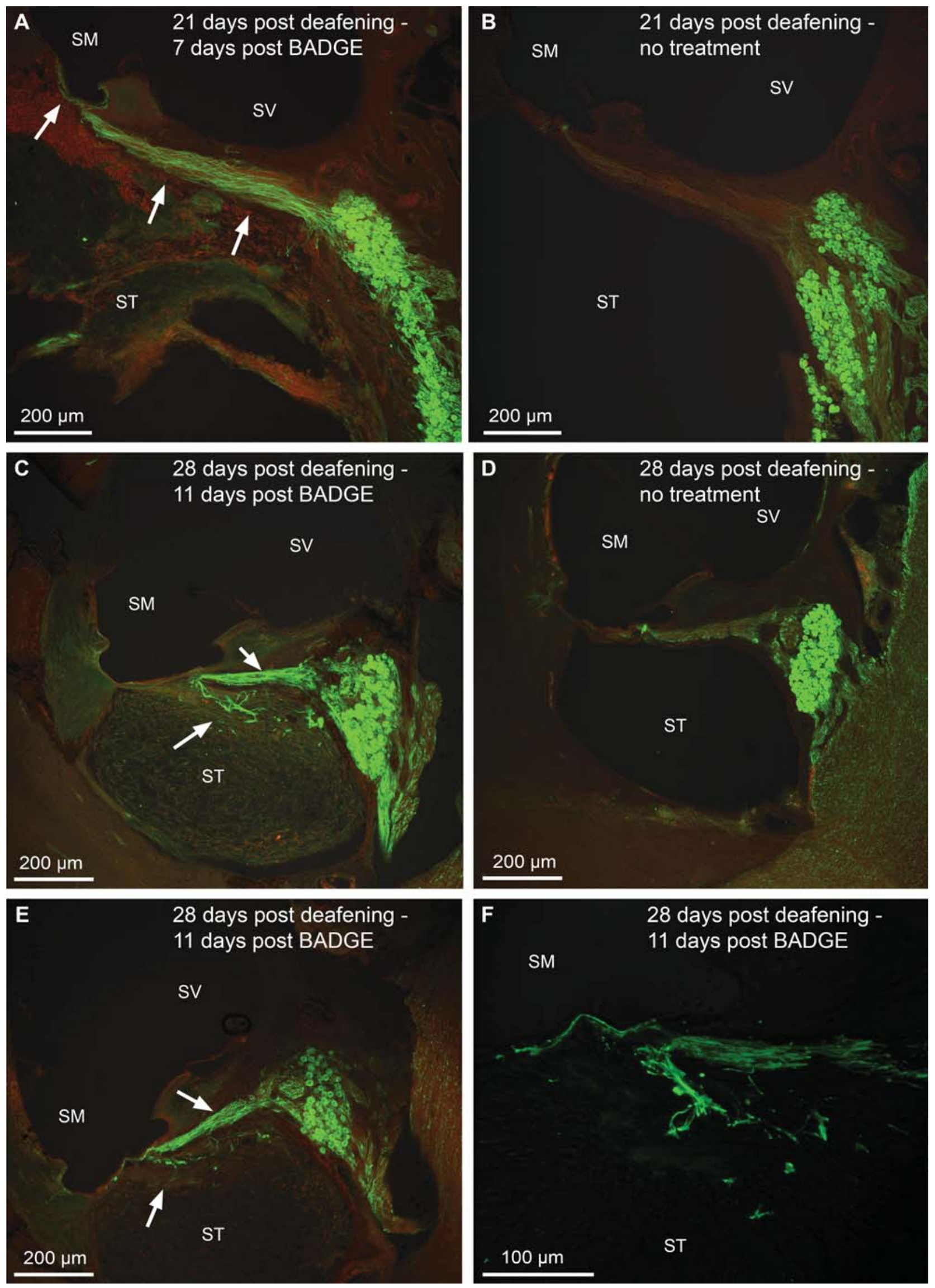



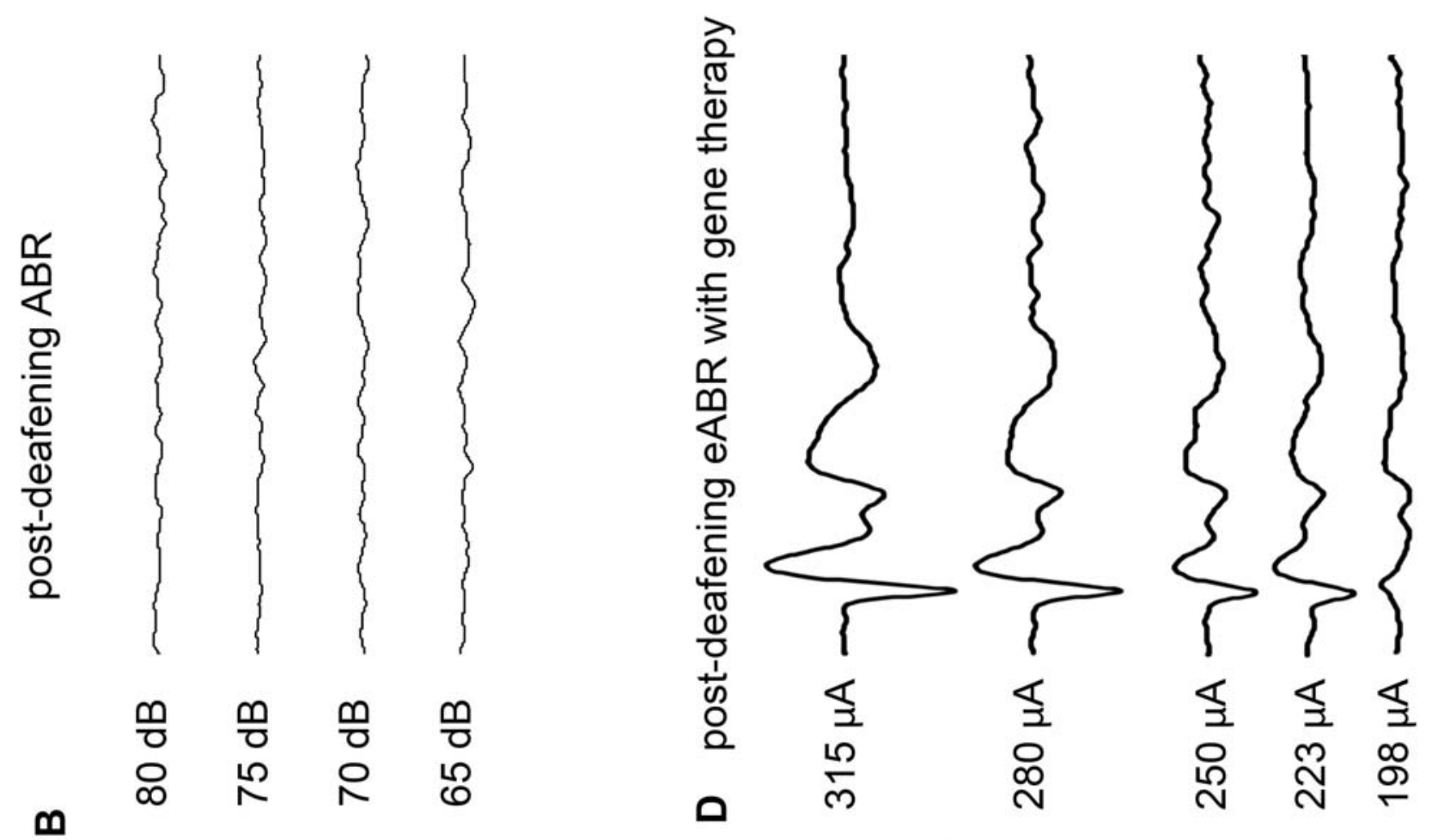

$\boldsymbol{m}$

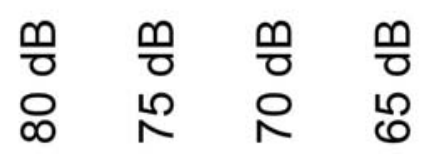

$$
\begin{array}{ll}
\gtreqless & \stackrel{n}{\xi} \\
- & -1
\end{array}
$$

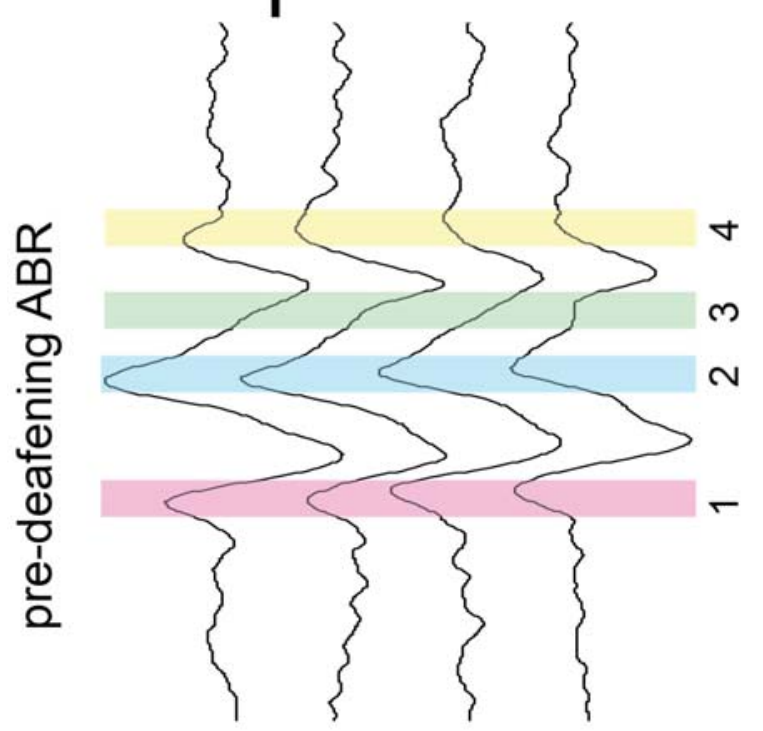

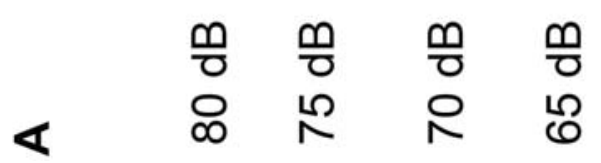
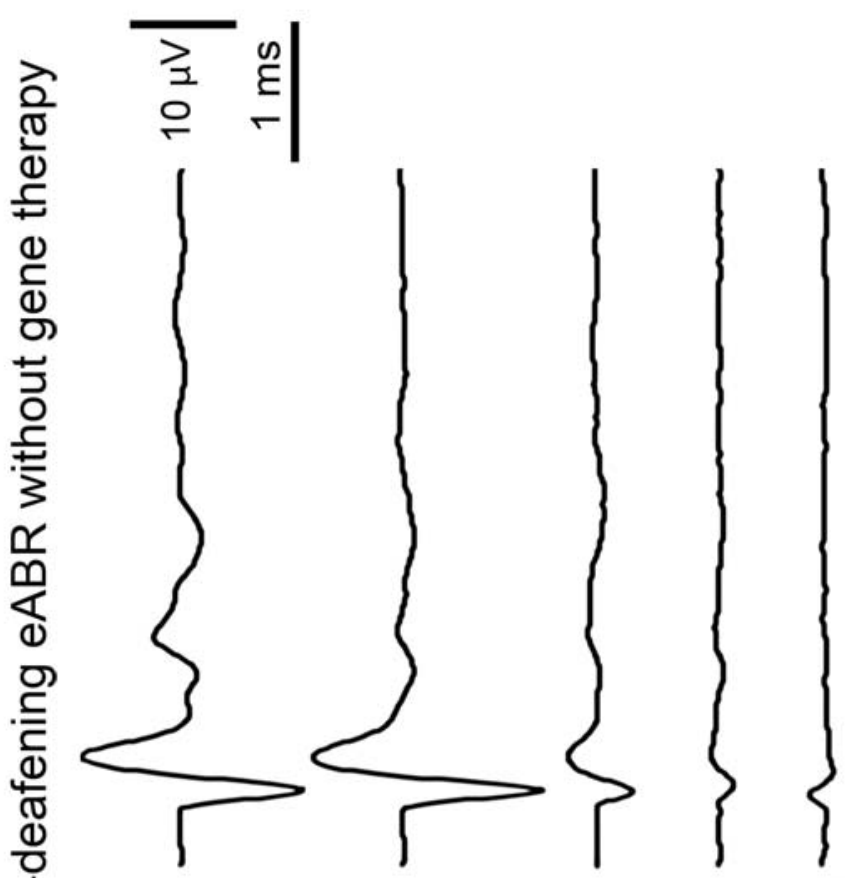

章

孚

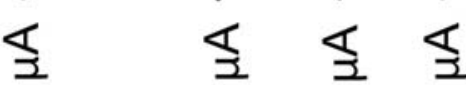

0 श

ठ্

命 


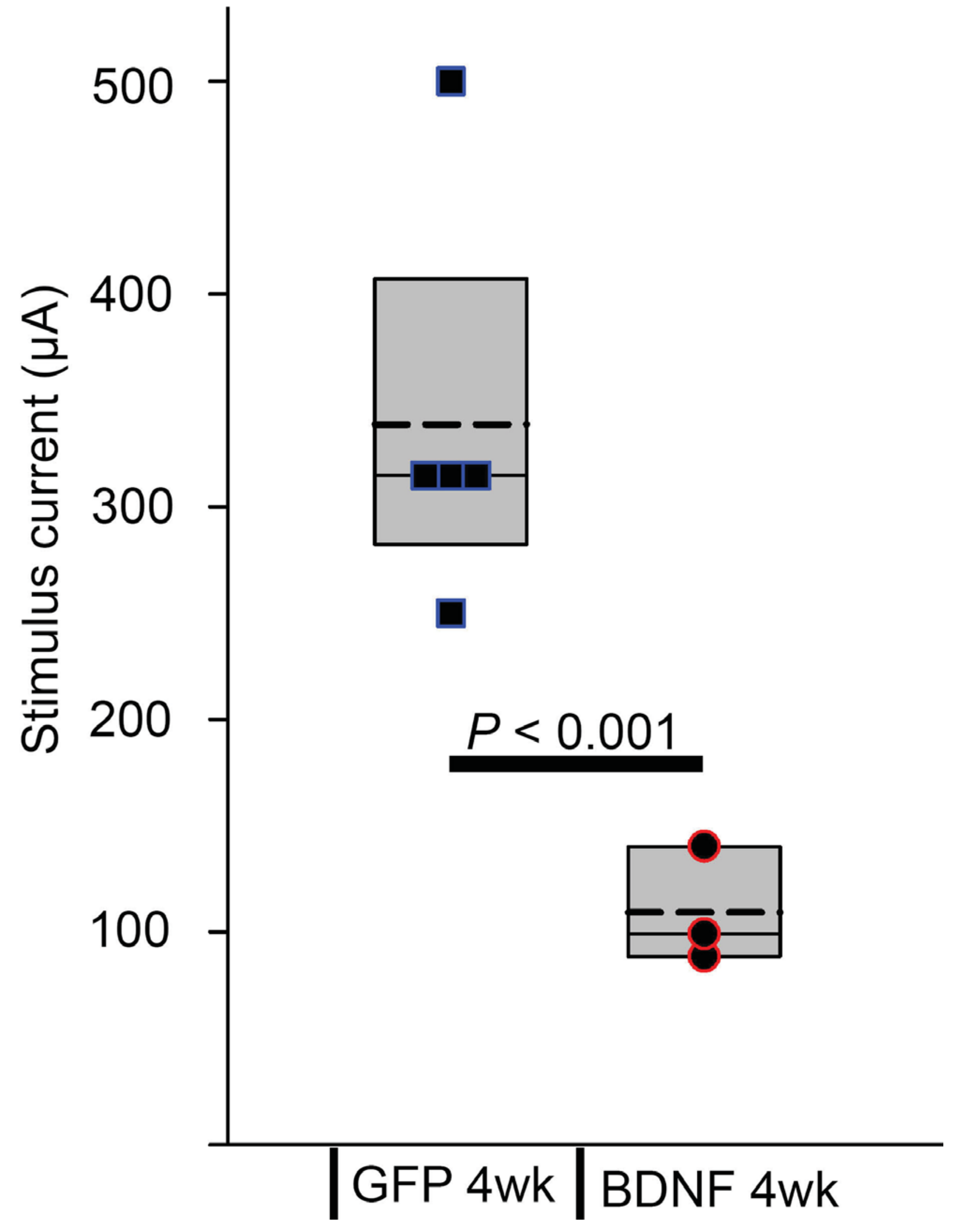


A

\section{Tandem}

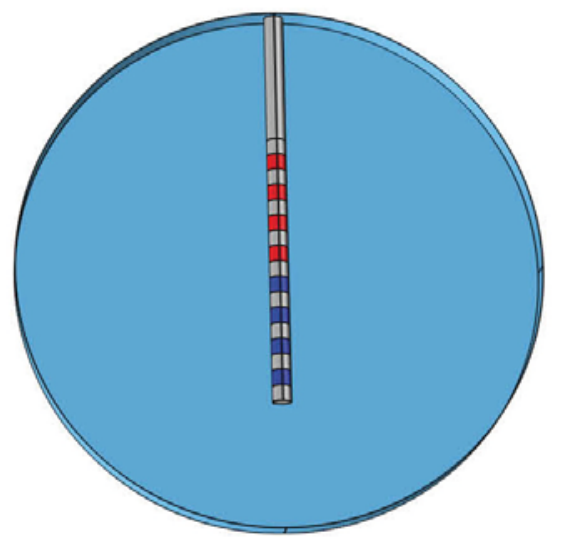

Electrode Configuration
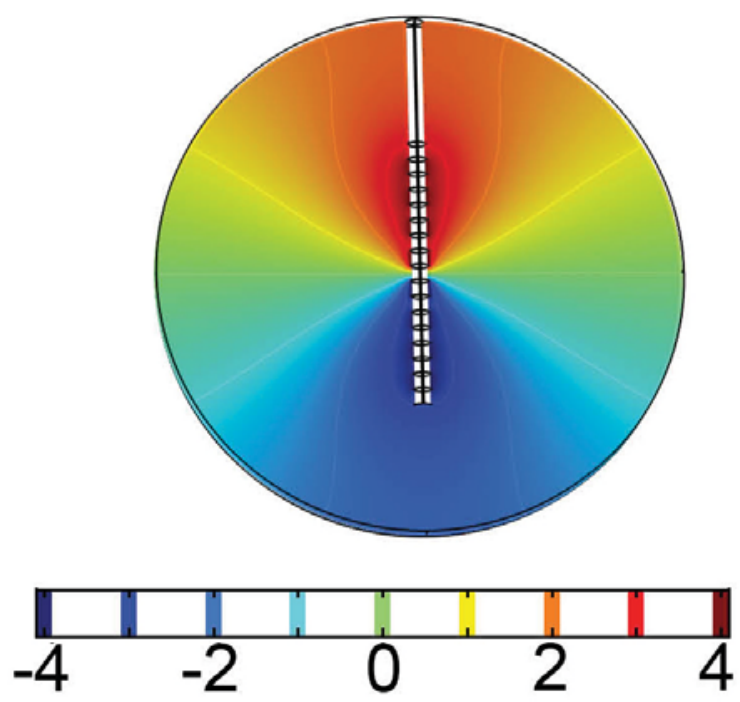

Field Potential (V)
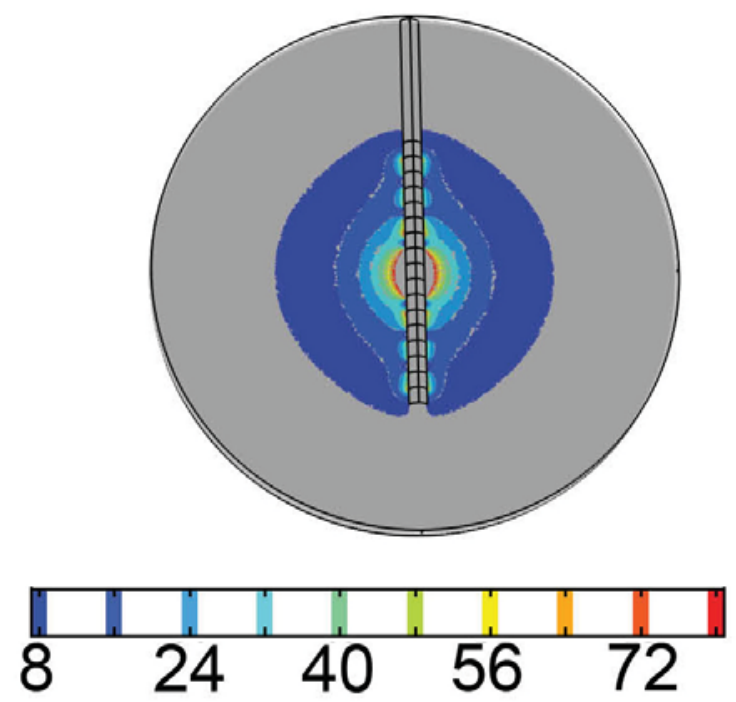

Electric Field (V/cm)
B Alternating

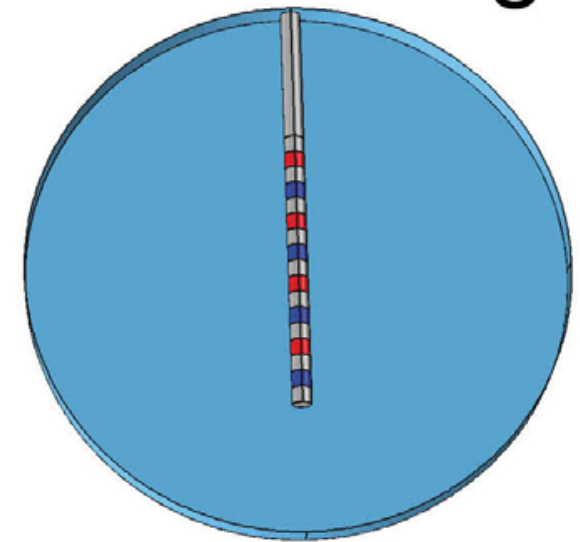

Electrode Configuration
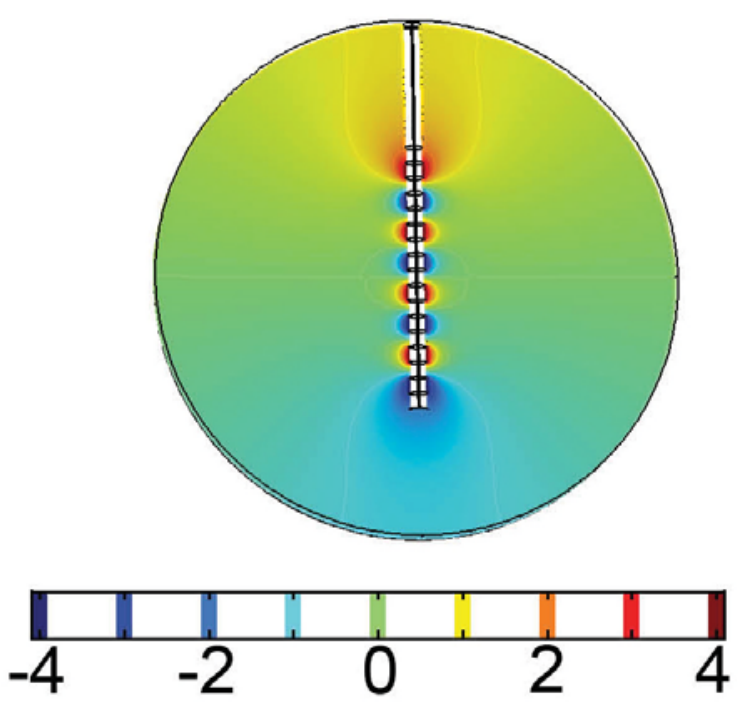

Field Potential (V)
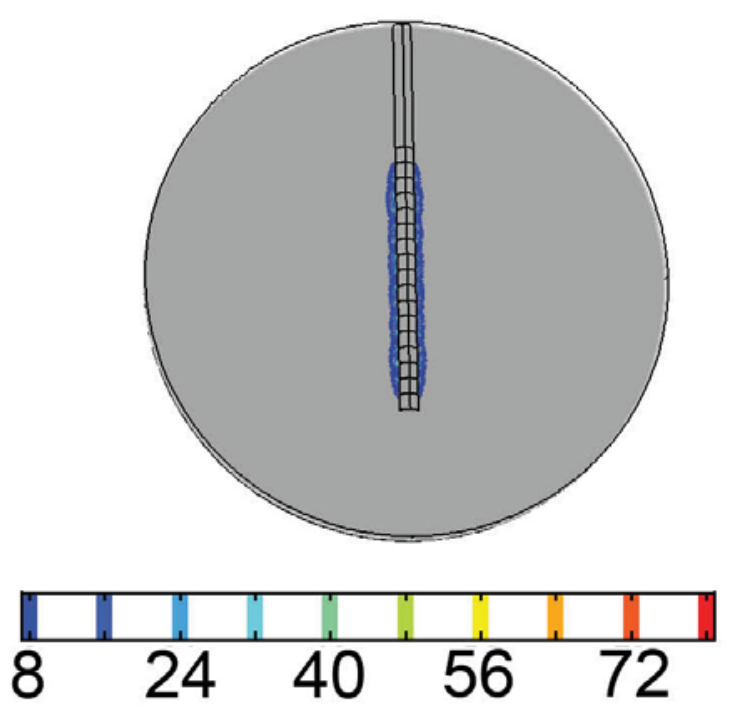

Electric Field (V/cm) 
HEK293 cell monolayer $40 \mathrm{~V} 5 \times 50 \mathrm{~ms}$ pulse

$2 \mathrm{~mm}$ 




